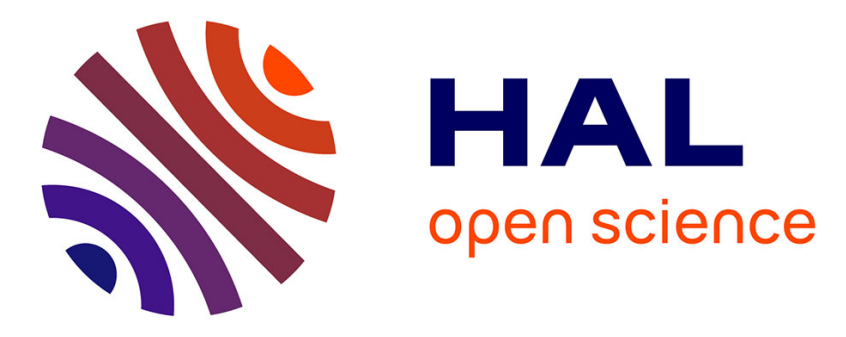

\title{
Development of a web-based collaboration platform for manufacturing product and process design evaluation using virtual reality techniques
}

Menelaos Pappas, Vassiliki Karabatsou, Dimitris Mavrikios, George

Chryssolouris

\section{To cite this version:}

Menelaos Pappas, Vassiliki Karabatsou, Dimitris Mavrikios, George Chryssolouris. Development of a web-based collaboration platform for manufacturing product and process design evaluation using virtual reality techniques. International Journal of Computer Integrated Manufacturing, 2006, 19 (08), pp.805-814. 10.1080/09511920600690426 . hal-00513378

\section{HAL Id: hal-00513378 \\ https://hal.science/hal-00513378}

Submitted on 1 Sep 2010

HAL is a multi-disciplinary open access archive for the deposit and dissemination of scientific research documents, whether they are published or not. The documents may come from teaching and research institutions in France or abroad, or from public or private research centers.
L'archive ouverte pluridisciplinaire HAL, est destinée au dépôt et à la diffusion de documents scientifiques de niveau recherche, publiés ou non, émanant des établissements d'enseignement et de recherche français ou étrangers, des laboratoires publics ou privés. 


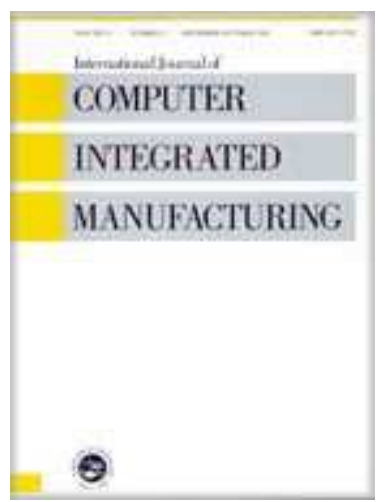

\section{Development of a web-based collaboration platform for manufacturing product and process design evaluation using virtual reality techniques}

\begin{tabular}{|r|l|}
\hline Journal: & International Journal of Computer Integrated Manufacturing \\
\hline Manuscript ID: & TCIM-2005-IJCIM-0028.R1 \\
\hline Manuscript Type: & Original Manuscript \\
\hline Complete List of Authors: & $\begin{array}{l}\text { Pappas, Menelaos; University of Patras, Mechanical Engineering and } \\
\text { Aeronautics } \\
\text { Karabatsou, Vassiliki; University of Patras, Mechanical Engineering } \\
\text { and Aeronautics } \\
\text { Mavrikios, Dimitris; University of Patras, Mechanical Engineering } \\
\text { and Aeronautics } \\
\text { Chryssolouris, George; University of Patras, Mechanical Engineering } \\
\text { and Aeronautics }\end{array}$ \\
\hline Keywords: & $\begin{array}{l}\text { DISTRIBUTED MULTI-AGENT SYSTEMS, VIRTUAL REALITY, } \\
\text { COLLABORATIVE MANUFACTURING }\end{array}$ \\
\hline Keywords (user): & $\begin{array}{l}\text { WEB-BASED PLATFORM, DISTRIBUTED COLLABORATIVE } \\
\text { ENVIRONMENTS }\end{array}$ \\
\hline
\end{tabular}

\section{s.) ScholarONE \\ Manuscript Central}


INT. J. COMPUTER INTEGRATED MANUFACTURING

\title{
Development of a web-based collaboration platform for manufacturing product and process design evaluation using virtual reality techniques
}

\author{
M. PAPPAS, V. KARABATSOU, D. MAVRIKIOS and G. CHRYSSOLOURIS*, \\ Laboratory for Manufacturing Systems and Automation (LMS), Department of Mechanical Engineering and \\ Aeronautics, University of Patras, Patras 26500, Greece \\ *Email: gchrys@hol.gr, xrisol@1ms.mech.upatras.gr
}

This paper describes the development of a web-based platform for collaborative process and product design evaluation. The Distributed Collaborative Design Evaluation (DiCoDEv) platform provides real-time collaboration of multiple users at different sites on the same project. The innovation concept of this platform lies in the use of Virtual Reality (VR) technology for the development of the working display environment that provides also navigation, immersion and interaction capabilities for all collaborative users in real time. The scope of this work is to provide an efficient robust collaboration tool for the real time validation of a manufacturing product or process, from the early stages of the conceptual design until the latest stages of the production chain. In order to demonstrate the benefits of the virtual collaboration that DiCoDEv platform can provide for manufacturing, a pilot case with a virtual reality environment has been developed based on the requirements of a "real life" manufacturing company.

Keywords: distributed multi-agent systems; collaborative manufacturing; virtual reality; web-based platform; distributed collaborative environments

\section{Introduction}

Today's global business environment in manufacturing industry is characterized by unprecedented competitive pressures and sophisticated customers, who demand innovative and speedy solutions. Understanding and optimizing design processes is a cornerstone of success in these fast-changing environments. A short time to market and maintaining a high quality level of a product have become the main success factors.

Thus, manufacturing companies need to innovate themselves frequently, both by designing new products and by enhancing the quality of the existing ones (Chryssolouris, 2005). Usually, during product design, all the persons involved share a great amount of drawings and assembly models. Often, different components or subassemblies of the product are designed by different groups of designers at geographically different locations. Companies are frequently out-sourcing engineering activities, performed internally, in order to accelerate the design and the product development process (Park et al. 1999). Nowadays, almost 50-80\% of all the components manufactured by original equipment manufacturers are out-sourcedo external suppliers (Rezayat 2000). 


\section{Pappas et al.}

However, this policy often creates many comprehension problems due to the lack of an internet based collaborative product design tool, which would effectively disseminate product design knowledge. These problems are typically resolved through meetings or via e-mails and phone discussions. Colleagues are not easily capable of collaborating and exchanging their ideas if they work in different places or even worst, in different countries. A web-based collaborative environment could solve this problem by eliminating unnecessary meetings, repetitive emails and costly product mistakes and delays. The use of such a system aims at identifying, quickly and efficiently, the feasible and the optimal designs through collaboration among product development partners at different locations.

The main goal of the present work is the conceptualization, design and development of a web-based platform for supporting both product data management and real-time collaboration into the same Virtual Environment. The DiCoDEv platform not only does it provide collaboration capabilities among multiple users via the internet, but also immersion and interaction with products and processes under evaluation, through the VRbased working environment. Collaboration features related to users, roles, events, projects and files management together with simulation features, related to process and product design verification using VR, have been developed and incorporated into the integrated web-based platform.

\section{Background work}

Various web-based manufacturing systems have been developed in the past decade for supporting collaborative activities in different life-cycle phases of product development, including marketing, design, process planning, production, distribution, service, etc., and associating these distributed product development life-cycle activities into a globally integrated environment using internet as well as web technologies (Chryssolouris et al. 2004). Many product development software systems, such as CAD, CAM, database management, intelligent knowledge-based, etc., have also been integrated, through web technologies, into these web-based collaboration systems (Yang et al. 2003).

An asynchronous collaborative system has been presented (Craig et al. 2002), called Immersive Discussion Tool (IDT), which emphasizes on the elaboration and transformations of a problem space and underlines the role that unstructured verbal communication and graphic communication can play in design processes. A prototypical system called cPAD has been developed (Shyamsundar et al. 2001, 2002) that enables designers to visualize product assembly models and perform real time geometric modifications, based on polygonized representations of assembly models. The Detailed Virtual Design System (DVDS) for shape modelling in a multi-modal, multi-sensory Virtual Environment (VE) has been presented (Arangarasan et al. 2000), enabling collaborative design and design among multiple designers both in the same site and in remote site virtual environments. An Internet-based virtual reality collaborative environment called Virtual-based Collaborative Environment (VRCE) developed with the use of Vnet, Java and VRML (Kan et al. 2001), demonstrates the feasibility of collaborative design for small to medium size companies that focus on a narrow range of low cost products. A web-enabled PDM system which facilitates various collaborative design activities (Xu et al. 2003) has been developed providing also 3D visualization capabilities. Another tool for dynamic data sharing in collaborative design has been developed (Noel et al. 2003), ensuring that experts may use it as a common space to define and share design entities. A web-based collaborative product design platform for dispersed network manufacturing has been proposed (Zhan et al. 2003). This platform enables authorized users in geographically different locations to have access to the company's product data, such as product drawing files stored at designated servers and to carry out product design work simultaneously and collaboratively on any operating systems.

Further to the research approaches to the field of a web-based collaborative product design, a few commercial tools are available to support such functionalities. OneSpace.net (http://www.cocreate.com/) is a lightweight web collaboration tool that supports online team collaboration for project development. It combines 


\section{Development of a web-based collaboration platform}

architecture for web services with familiar concepts, such as organized projects, secure messaging, presence awareness and real time online meetings. IBM's Product Lifecycle Management Express Portfolio is designed specifically for medium-sized companies that design or manufacture products. This system mainly focuses on business processes but also allows design engineers to share 3D data, created with diverse authoring tools and thus, product development can be managed. It includes CATIA Version 5 collaborative product design software and SMARTEAM for product data and release management (http://www.ibm.com/). Matrix10 is designed to support deployments of all sizes. It includes PLM business process applications that cover a wide range of processes including product planning, development and sourcing and program management. The tool furthermore, allows diverse design disciplines to be synchronized around design activities and changes, by reducing the critical errors and cost associated with poor collaboration (http://www.matrixone.com/). eDrawings Professional (http://www.solidworks.com/) is an email-enabled communication tool that eases the review of 2D and 3D product design data across extended product development teams.

Despite the investment made in the last years, both in research and in industrial fields, the global market still lacks in collaboration tools, capable of providing virtual reality techniques as well for product and process design evaluation. Most collaborative tools are more related to a Product Lifecycle Management and less to a purely web-based collaborative platform. Thus, the development of a lightweight web platform that supports the collaborative management, validation and dissemination of product designs/projects as well as the immersive interaction of multiple users with the virtual prototypes, comprise the goals of this research work.

\section{Platform implementation}

The DiCoDEv platform was designed based on an open architecture and Browser/Server technology. The development of the DiCoDEv platform was driven by standard technologies applied to the J2EE language. Such technologies include Java Server Pages (JSP) for visualizing data by creation of HTML pages and Servlets for data manipulation and user interaction. For the Web Server and Servlets container 'Apache Jakarta Tomcat 4.0.4' was used. The development was assisted by 'Borland JBuilder X' as the Integrated Development Environment (IDE) and InterDev together with Oracle 9i development and administration tools for the database design and creation. The development as well as the installation took place on Windows XP Professional Edition operating systems but the same tools, technologies and development processes could be applied to other operating systems, such as Unix.

\subsection{Architecture}

The web platform architecture is following the 3-tier example and includes three layers (Figure 1):

- The Data Layer

- The Business Layer, and

- The Presentation Layer

[Insert figure 1 about here]

These layers communicate through Internet or Intranet, depending on the type of communication.

- Data layer (1st tier): includes the application's database and the connections with all the other external systems as for example an external database for the recovery and storing of data. Some characteristics, such as data locking, consistency and replication ensure the integrity of data. Oracle 9i was used for the platform's database implementation.

- Business layer (2nd tier): consists of the business logic. The architecture of this level can be divided and analyzed furthermore into: The connection mechanism between the mainframe PC and the 
M. Pappas et al.

application (JavaServer), the Java Bean Architecture, which contains the work-division planning algorithm and the database interactions, and finally an independent XML unit, which is going to manage the connection between the platform database and the external applications.

- Presentation layer (3rd tier): concerns the clients and consists of the Netscape and Internet Explorer web browsers for this application.

\subsection{User workflow}

The connection among users complies with the Browser User Interface (BUI) models, in a user-friendly Windows environment, which allows the exploitation of all net-place capabilities by using any desired web browser. The user workflow is presented in Figure 2.

User Home Page is the first page and presents information about the number of the new messages in the user's inbox and the number of projects that he/she participates in. Through the Manage Profile page users can change their personal profile. Users can also manage (send/view) all their messages for all the projects they participate in, through the message pages (Manage Messages \& Send/View Message). Once a user has been authorized to the platform he/she is able to participate in an on-line communication and cooperation by exchanging thoughts and ideas with other authorized users through the Chat page. A list of the online users also appears in this page. Moreover, users are able to join specific project-related chat channels.

\section{[Insert figure 2 about here]}

All projects that a user participates in are presented in a list form, in the Manage Workspace page. Information, such as the project's description, the owner and starting date, also appear in this list. If a user is the project owner then he/she has the right to modify the project-related information (name, description, etc.) through the Manage Project page, otherwise he/she can only view this data.

[Insert figure 3 about here]

Through the Manage Users page, the project owners can add/remove active users to their own project, from the list of the authorized users and select their roles for the specific project. Roles are project-related and are specified by the project owners. Through the Manage Project Versions page, the users can manage (view, delete or create) project versions with respect to their authorities in the specific project. The Manage Project Pool page enables users to upload and download files of any type that could be used by all authorized users during the collaborative design process.

In most of the pages, search function and filters are available in order to make the search for specific information easier.

\subsection{Virtual environment}

In order for the DiCoDEv platform to provide virtual collaboration, a commercial VR software tool (DIVISION MockUp2000i2 or dv/MockUp of PTC - http://www.ptc.com/), is used as a basis for the visualisation and development of the virtual project environments. Ergonomics evaluation of product's design can be also performed in the virtual environment by using an appropriate digital human tool. This system has been integrated into the web platform so as to be directly accessed by users through the platform's GUI. The virtual project environment is used for the visualisation and simulation of products and processes during a collaborative design evaluation scenario. The users are able to create, open, view, modify and save the virtual project environment they work on. All collaborative distributed users can work on the same environment in 
real-time either in desktop (Figure 4) or immersive mode, using VR peripheral devices (i.e. Head Mounted Displays, Motion Tracking Systems, Navigation Devises, Data Gloves). A pilot case demonstrating the virtual collaboration capabilities of the DiCoDEv platform is presented in section 5.

[Insert figure 4 about here]

\subsection{Communication}

The communication between the front-end and the platform's database is achieved by Oracles' drivers. The web interface provides access to the portal and runs on a Windows 2000 or XP Operating System. A 128kbps ISDN (or DSL) line is capable of confronting with the data load during a collaborative session. Through this communication, the authorized users can upload/download the required virtual project environment and information. By the time the project-related files are uploaded, a new version of the selected project is automatically created into the database.

The communication between the front-end and the back-end external application (dv/MockUp) enables authorized users to open and modify a virtual project environment and it is realized through the XML protocol (Figure 5).

Communication between the DiCoDEv platform and other external applications, such as databases is also feasible.

[Insert figure 5 about here]

\section{Platform functionality}

The key features of the DiCoDEv platform have been implemented so as to cover both the development standards of the web-based applications and the requirements of a typical industrial virtual collaborative scenario.

\subsection{Collaborative functions}

The developed collaborative functions enable the management of users and data as well as real-time collaboration. The supported collaboration functions are:

- Security: The Platform Administrator has the overall security management of the system and provides the users with passwords. Every user has to give his login and password in order to have access to the platform's data. Moreover, in order to eliminate spamming phenomena, filters and disk-storage limitations are provided.

- Users/roles management: This function enables the management of the security and the rights on every file within a project depending on the predefined role of each user. Based on the user's role, the system provides him/her with specific access rights to the various platform's features, information and capabilities.

- Messages/chat: E-mails and chat (Figure 6) are supported to enable authorized users to communicate with each other. This function allows participants to exchange easily and quickly ideas about a new product and improves decision making in product or process design verification, allowing issues that could hinder a project's progress to be quickly removed by team members. 


\section{Pappas et al.}

[Insert figure 6 about here]

- File sharing: This function enables authorized users to easily send and receive large files via internet without the hassle of FTP or the limitations of the e-mails' providers.

- File storage/versioning: File storage and versioning is provided through the platform's database. Several types of files (drawings, documents, 3D models, textures, etc.) could be stored and retrieved by the users. An automatic and easy-to-use mechanism for file versioning has been developed in order to help involved users to review the history of modifications of every project-related file.

- File browser/info: A user friendly web-based interface allows authorized users to create, delete, edit, copy, rename, move, download and upload files and directories. It has been designed for rapid adoption throughout an organization, requiring little or no training to get familiar with it in order to enable the quick search of any required information stored into the database.

\subsection{Virtual reality functions}

These functions have been implemented into the dv/MockUp to allow the visualisation and functional simulation of products and processes as well as the users' immersion and interaction within the virtual environment. The basic Virtual Reality functions are:

- Behavioural simulation: Behavioural simulation controls the functional characteristics of the virtual systems involved in the process performance. Based on the event/action engine of $\mathrm{dv} / \mathrm{MockUp}$, developers can model complex behaviours in the virtual environment (assembly joint constraints, part movement restrictions etc.), in order for the virtual objects to 'behave' in a real-life like manner.

- Assembly: This function allows the accurate assembly execution within the virtual environment. During an assembly process, the part to be assembled is released from the user's hand, so as to be assembled in its final position, as soon as a good positional and rotational orientation has been achieved (magnet concept). This orientation is very close to the exact final mounting position. The field of the 'magnet' can be adjusted to account for various levels of fitting precision (Figure 7).

[Insert figure 7 about here]

- Collision detection: Dynamic clash detection is provided within the simulation environment among static parts and either moving parts or the user's hands. In this way, visual and acoustic alerts enable the user to verify the feasibility of a process, in terms of reachability of picking and mounting locations and handlability of parts.

\section{Pilot application}

In order to demonstrate the benefits of the virtual collaboration that DiCoDEv platform can provide for manufacturing, a virtual reality environment has been developed based on the requirements of a commercial refrigerators' company. The environment represents a typical milk-shop with refrigerators (Figure 8) and collaboration has been performed between different users in order to review these refrigerators in terms of design (i.e. capacity, ergonomics, door handle selection, etc.) and of appearance (i.e. colors, textures, logos, materials, etc.) before proceeding in the production phase.

[Insert figure 8 about here] 


\section{Development of a web-based collaboration platform}

Several collaborative sessions have been performed showing the capability of real-time collaboration among different users. They can use all the virtual reality functions of the environment (Figure 9) as well as the ergonomics evaluation, using digital humans in the virtual environment (Figure 10). Immersion capability is also available for realistic human interaction.

[Insert figure 9 about here]

[Insert figure 10 about here]

During a multi-user collaborative session, each participant has its own copy of the graphical user interface (GUI), which provides a rendered 3D view of the virtual product. All users can interact with the virtual product at any time, with no restriction on the number of simultaneous interactions. The changes made by a user are immediately visible to the others. Real-time chat capabilities enable the continuous communication among the online users. Moreover, a user can be represented by an animated manikin figure called avatar. Any number of users can join a collaborative session using TCP/IP over local or WAN networks. In order to use the DiCoDEv platform there is no enforcement on the use of specific Operational System or VR peripherals.

The integration of the DiCoDEv platform with Virtual Reality provides an advanced environment in the network as a common virtual design space in which people can simultaneously work during the product life cycle. The developed pilot environment enables:

- The cooperation among distributed designers and manufactures during the refrigerator design stage

- The real-time multi-user interaction into the same virtual prototype/design

- The effective and efficient use, sharing, and simulation of design and manufacturing data through the web (e.g. ideas, drawings, 3D-models, analysis results, ...)

- The ergonomics evaluation of the products using digital humans (manikins) that represent different user populations

- Activities in a many-to-many session within a common virtual space (e.g. conceptual design, virtual prototyping, assembly execution, ergonomic analysis, ...)

- The exchange of ideas and of comments based on the 3D representation of the product

- The advanced product demonstration through the web (a virtual web showroom)

\section{Conclusions}

In this paper, a web-based virtual collaborative platform called DiCoDEv - Distributed Collaborative Design Evaluation platform that can be used during manufacturing product and process design evaluation, is presented. Providing a multi-user real-time collaboration as well as a VR-based product and process verification, this platform is an integrated tool for designers, engineers and managers.

The DiCoDEv platform allows multiple users to work in collaborative and distributed way, decreasing considerably the time required for the designing phase to be completed. This work focuses on improving team productivity, providing the infrastructure necessary to make the engineering teams efficient, even if they are dispersed over different sites, without changing the existing design environment. The platform's integration into the VR environment enables the immersion and interaction of users with the virtual prototypes that lead to the efficient evaluation of product and process designs where the human intervention is crucial. The benefits of using the virtual capabilities of the DiCoDEv platform include:

- Multi-user visualization, immersion and interaction

- Real-time collaboration on the same virtual design 


\section{Pappas et al.}

- Simultaneous review and maintain alternative virtual designs

- Ergonomics evaluation using digital human simulation

\section{Acknowledgement}

This work was partially supported by the Greek national research project e-MERIT/EB-26, funded by the General Secretariat of Research and Technology (GSRT).

\section{References}

Arangarasan, R. and Gadh, R., Geometric modelling and collaborative design in a multi-modal multi-sensory virtual environment, in proceeding of the ASME 2000 Design Engineering Technical Conferences and Computers and Information in Engineering Conference, 2000, pp. 10-13.

Chryssolouris, G., Manufacturing Systems: Theory and Practice, $2^{\text {nd }}$ edition. 2005 (Springer-Verlag: New York).

Chryssolouris, G., Makris, S., Xanthakis, V. and Mourtzis, D., Towards the internet based supply chain management for the shiprepair industry. International Journal of Computer Integrated Manufacturing, 2004, 17(1), 45-57.

Chryssolouris, G., Makris, S., Papakostas, N. and Xanthakis, V., A cooperative software environment for planning and controlling ship-repair contracts, in proceedings of the 4th International Conference on e-Engineering \& Digital Enterprise Technology, 2004, pp. 321-330.

Craig, D. L. and Craig, Z., Support for collaborative design reasoning in shared virtual spaces. Automation in Construction, 2002, 11(2), 249-259.

Kan, H. Y., Duffy, V. G. and Su, C. J., An internet virtual reality collaborative environment for effective product design. Computers in Industry, 2001, 45, 197-213.

Noel, F. and Brissaud, D., Dynamic data sharing in a collaborative design environment. International Journal of Computer Integrated Manufacturing, 2003, 16(7-8), 546-556.

Park, H. and Cutkosky, M. R., Framework for modeling dependencies in collaborative engineering processes. Research in Engineering Design - Theory, Applications, and Concurrent Engineering, 1999, 11, 84102.

Rezayat, M., The enterprise - web portal for life cycle support. Computer Aided Design, 2000, 32(2), 85-96.

Shyamsundar, N. and Gadh, R., Internet-based collaborative product design with assembly features and virtual designspaces. Computer Aided Design, 2001, 33, 637-651.

Shyamsundar, N. and Gadh, R., Collaborative virtual prototyping of product assemblies over the Internet. Computer Aided Design, 2002, 34, 755-768.

$\mathrm{Xu}, \mathrm{X}$. W., and Liu, T., A web-enabled PDM system in a collaborative design environment. Robotics and Computer-Integrated Manufacturing, 2003, 19(4), 315-328.

Yang, H. and Xue, D., Recent research on developing Web-based manufacturing systems: a review. International Journal of Product Research, 2003, 41(15), 3601-3629.

Zhan, H. F., Lee, W. B., Cheung, C. F., Kwok, S. K. and Gu, X.J., A web-based collaborative product design platform for dispersed network manufacturing. Journal of Materials Processing Technology, 2003, 138, 600-604. 


\section{Development of a web-based collaboration platform}

Figure 1: 3-tier system architecture

Figure 2: DiCoDEv platform user workflow

Figure 3: Manage Project page

Figure 4: Collaborative design through the DiCoDEv platform

Figure 5: Interface between web-platform's GUI and dv/MockUp

Figure 6: Chat page of DiCoDEv web platform

Figure 7: Visualization of the assembly function (magnet concept)

Figure 8: Virtual environment of the pilot application

Figure 9: Real-time collaboration capability

Figure 10: Ergonomic analysis of the final product 
M. Pappas et al.

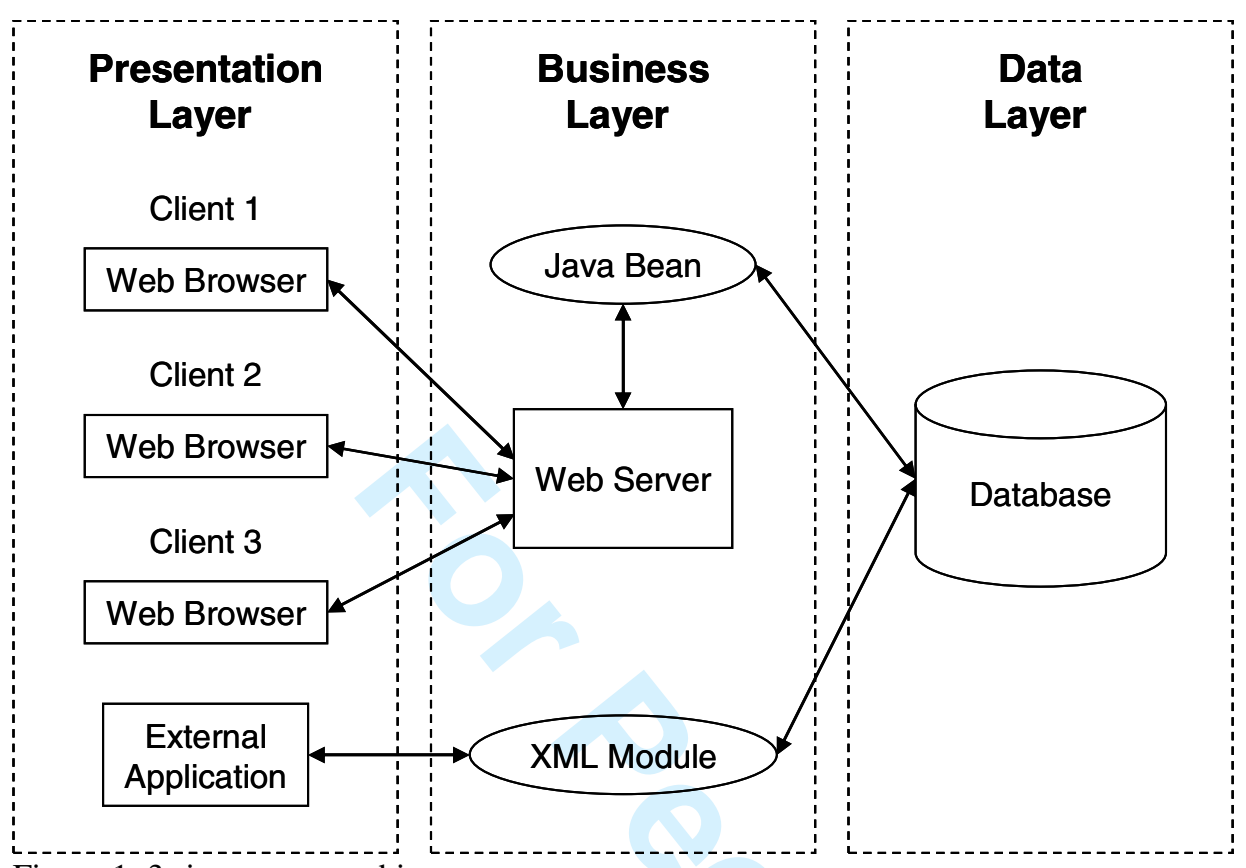

Figure 1: 3-tier system architecture 


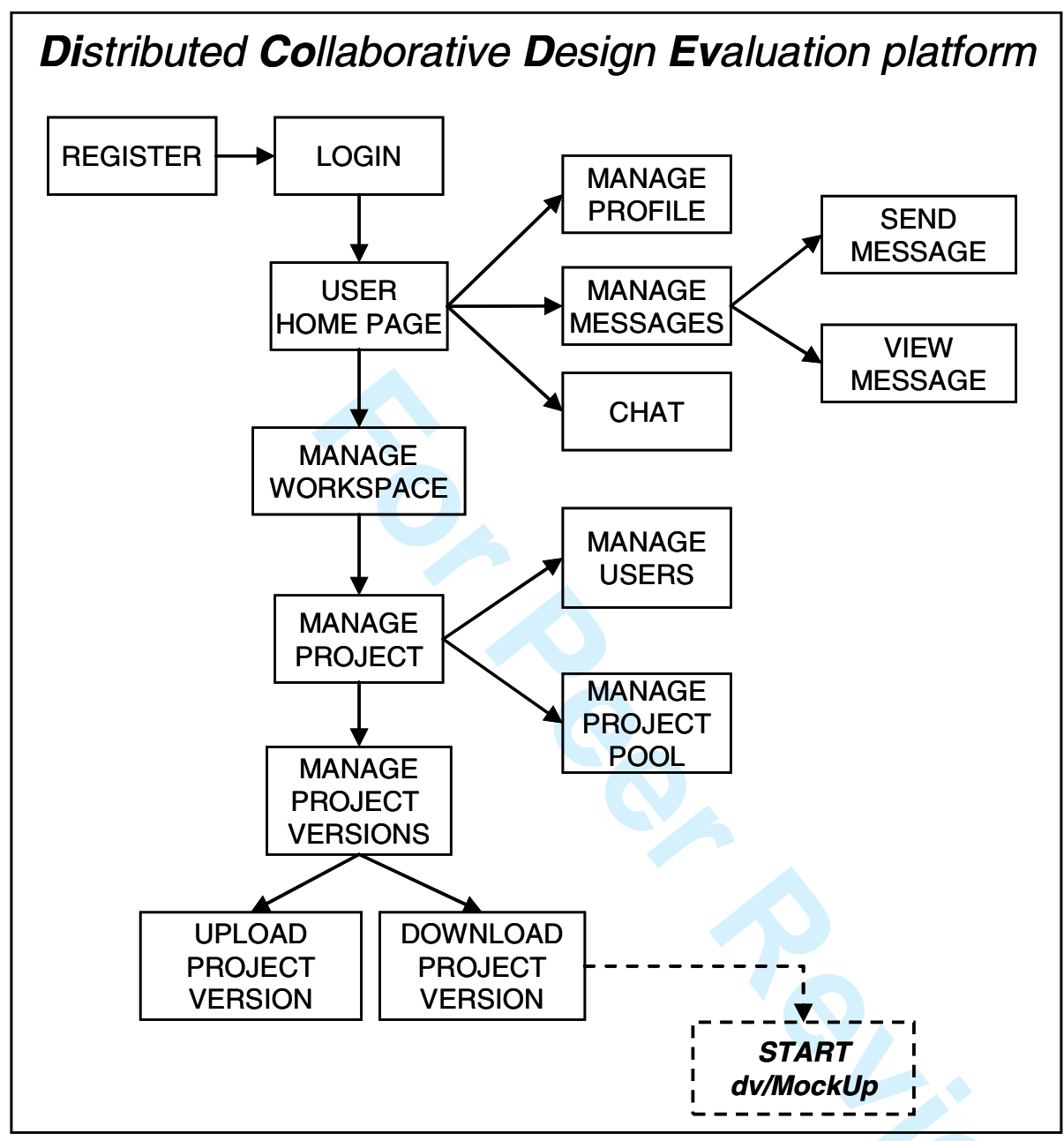

Figure 2: DiCoDEv platform user workflow 
M. Pappas et al.

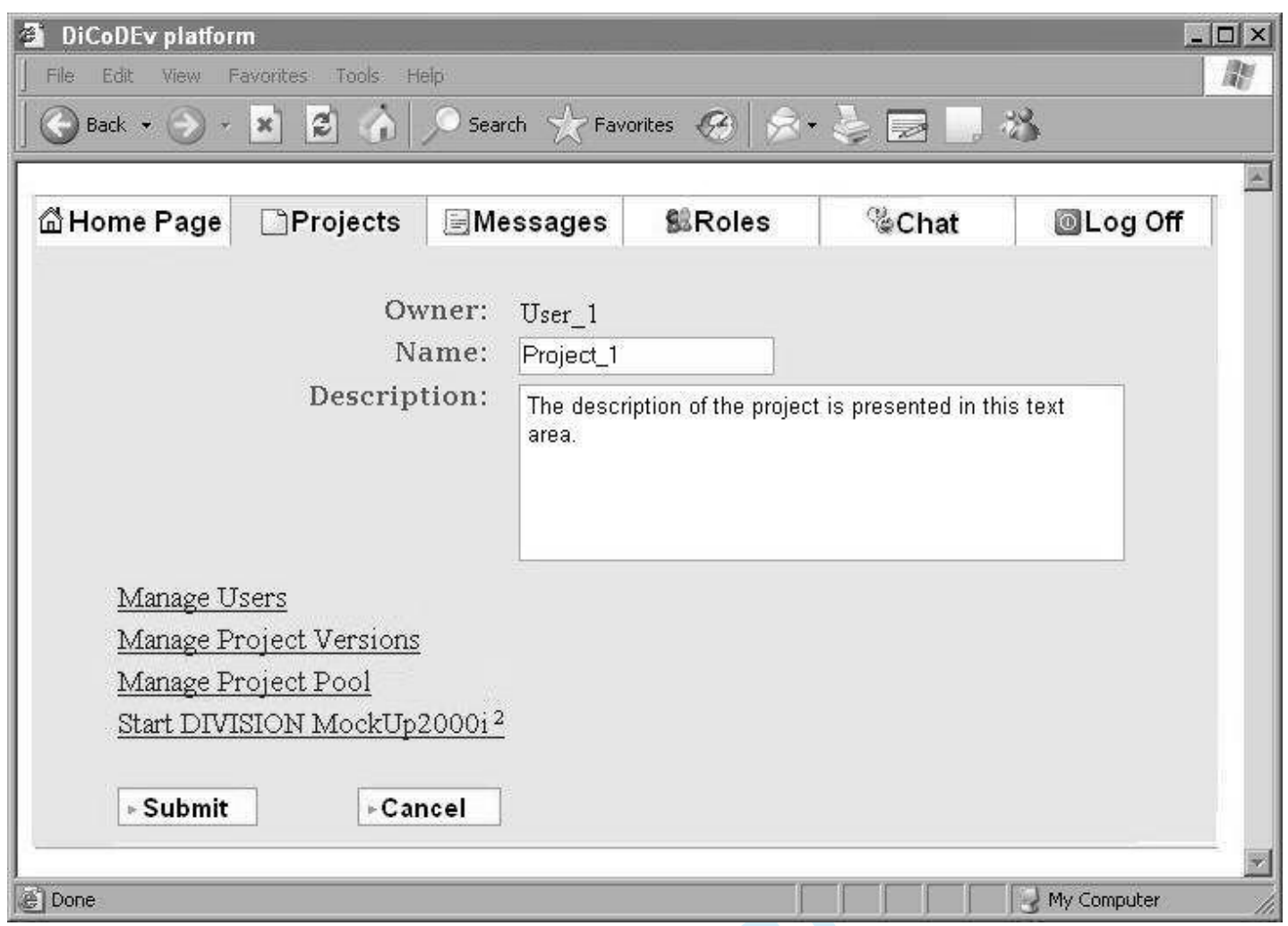

Figure 3: Manage Project page 
Development of a web-based collaboration platform

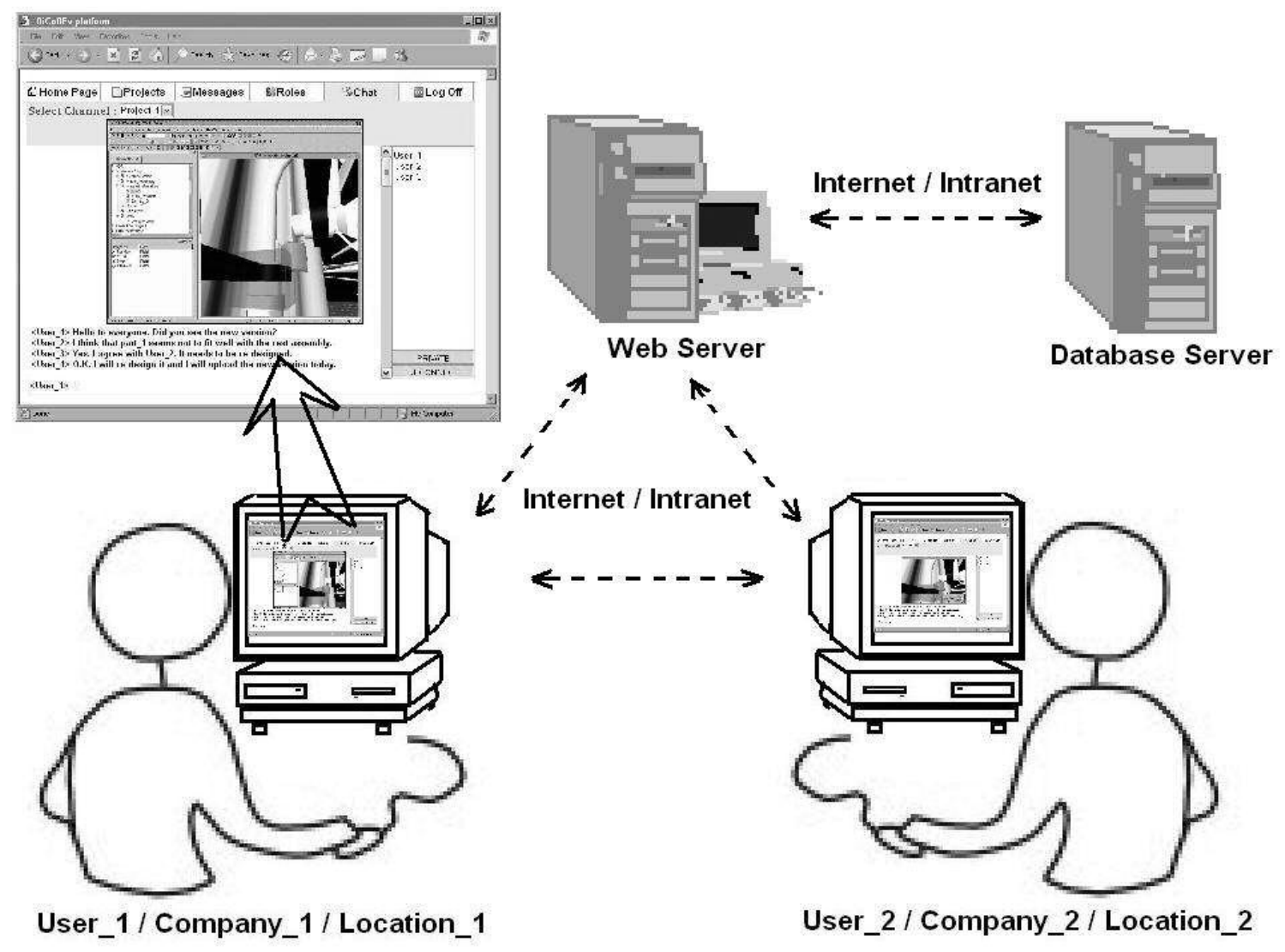

Figure 4: Collaborative design through the DiCoDEv platform 
M. Pappas et al.

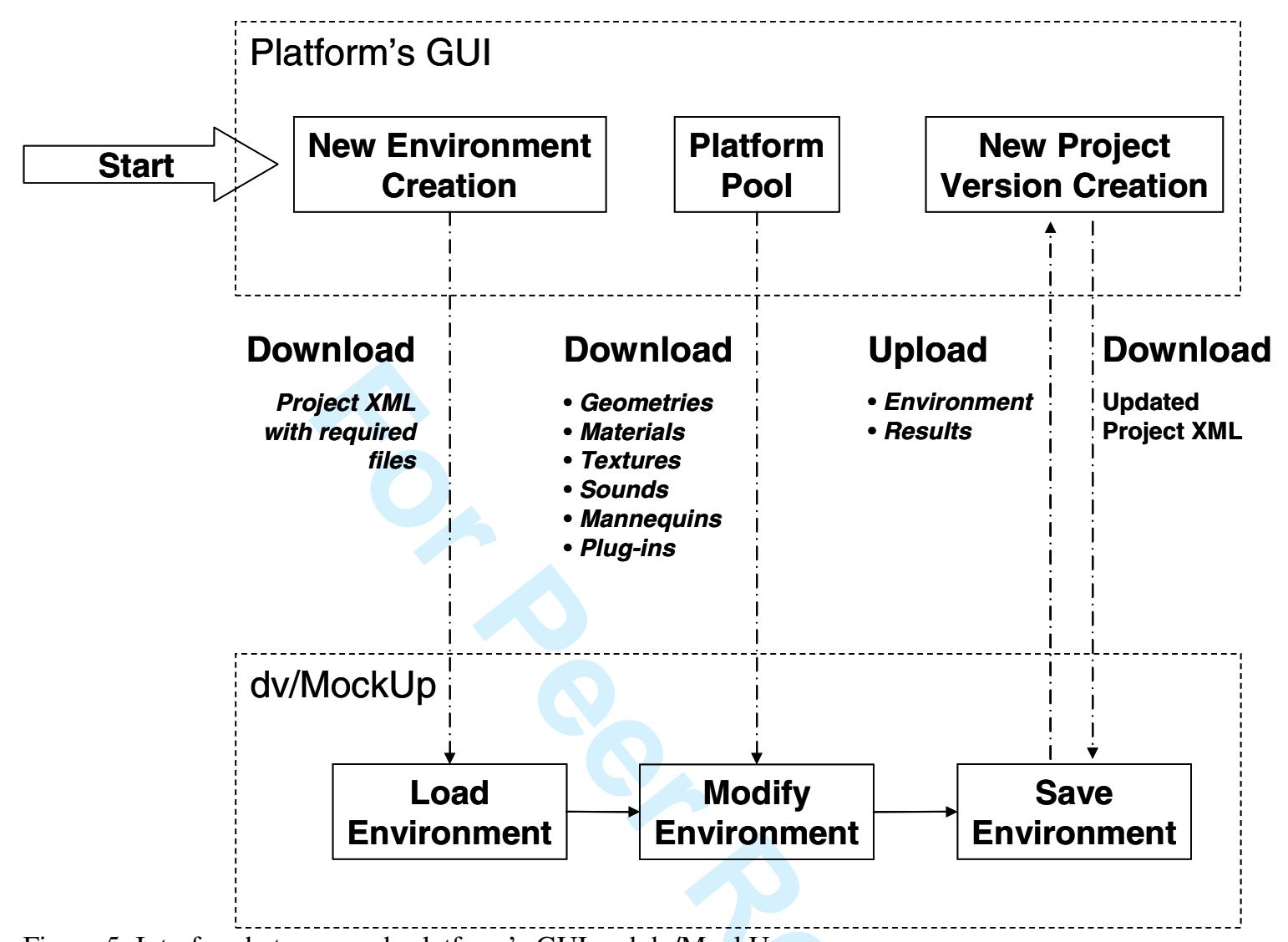

Figure 5: Interface between web-platform's GUI and dv/MockUp 
Development of a web-based collaboration platform

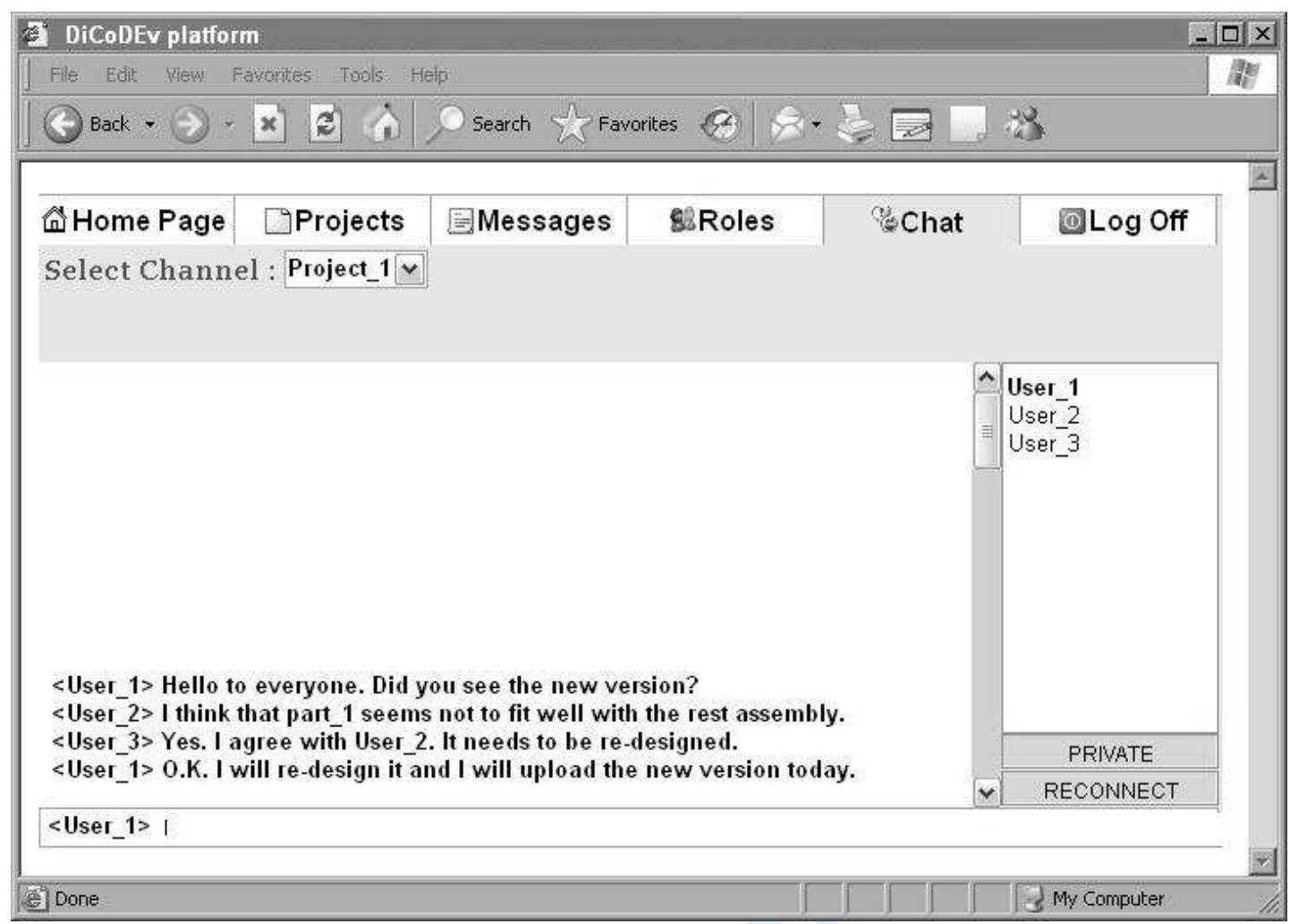

Figure 6: Chat page of DiCoDEv web platform 
M. Pappas et al.

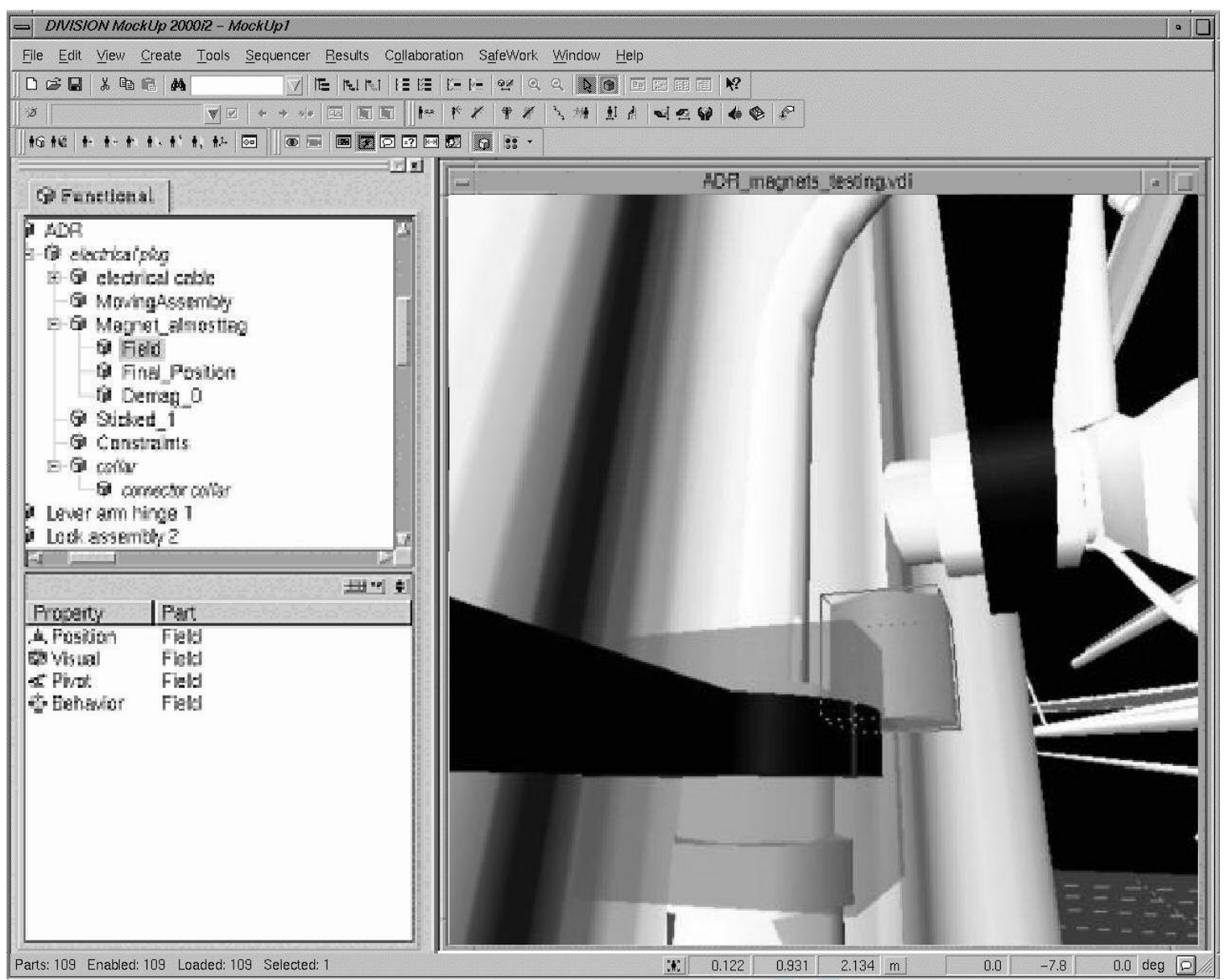

Figure 7: Visualization of the assembly function (magnet concept) 
Development of a web-based collaboration platform

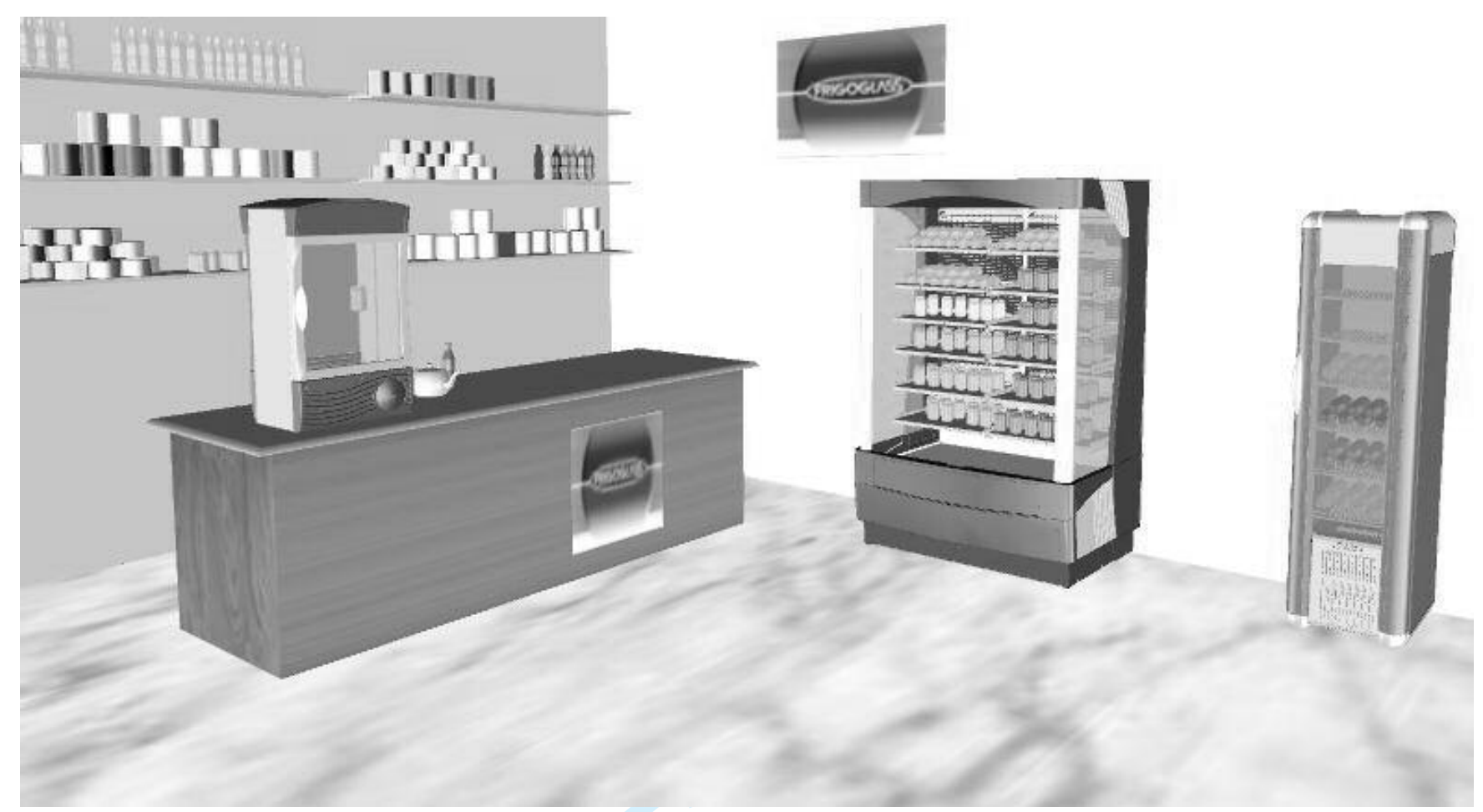

Figure 8: Virtual environment of the pilot application 
M. Pappas et al.

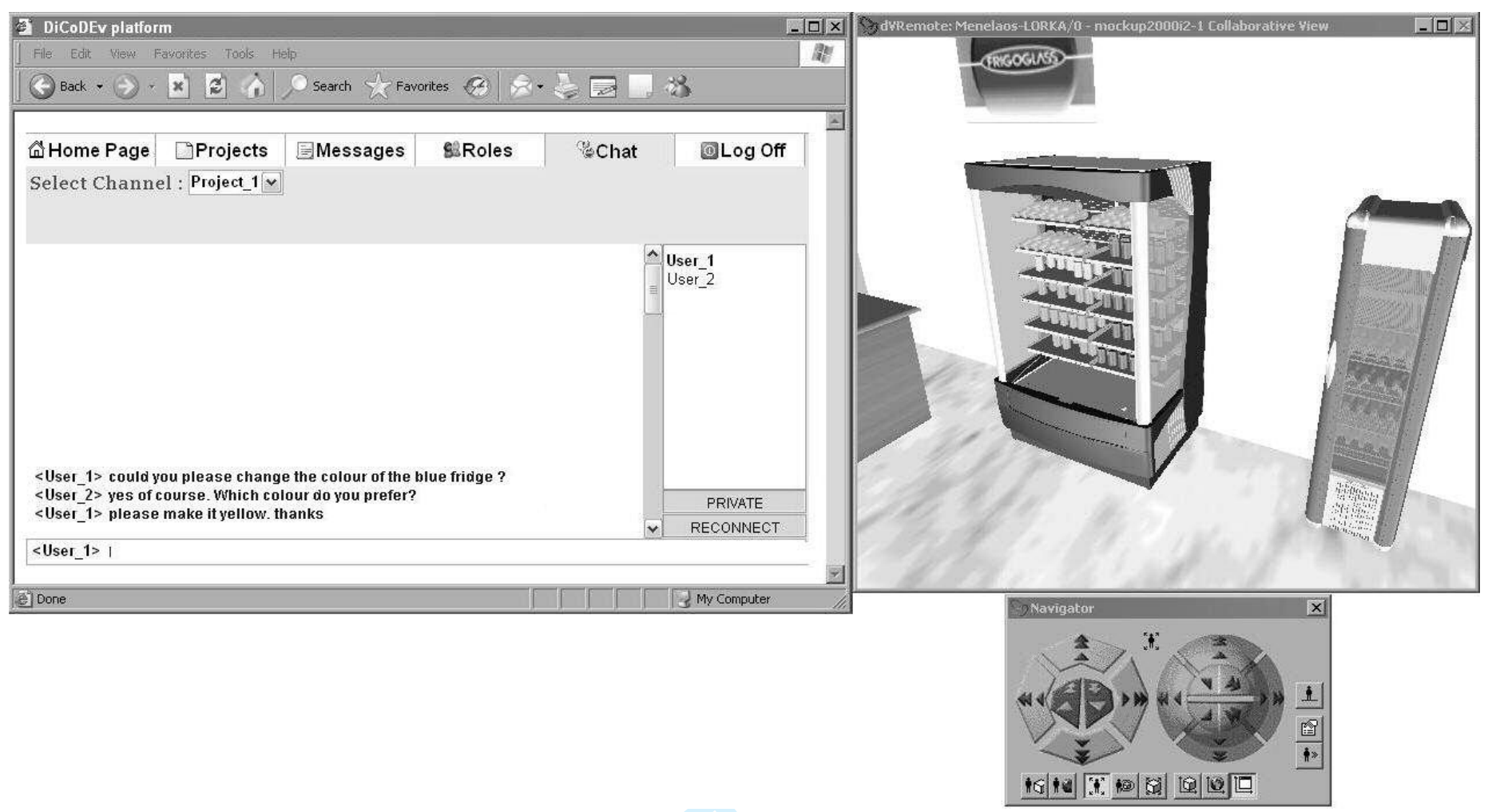

Figure 9: Real-time collaboration capability 
Development of a web-based collaboration platform

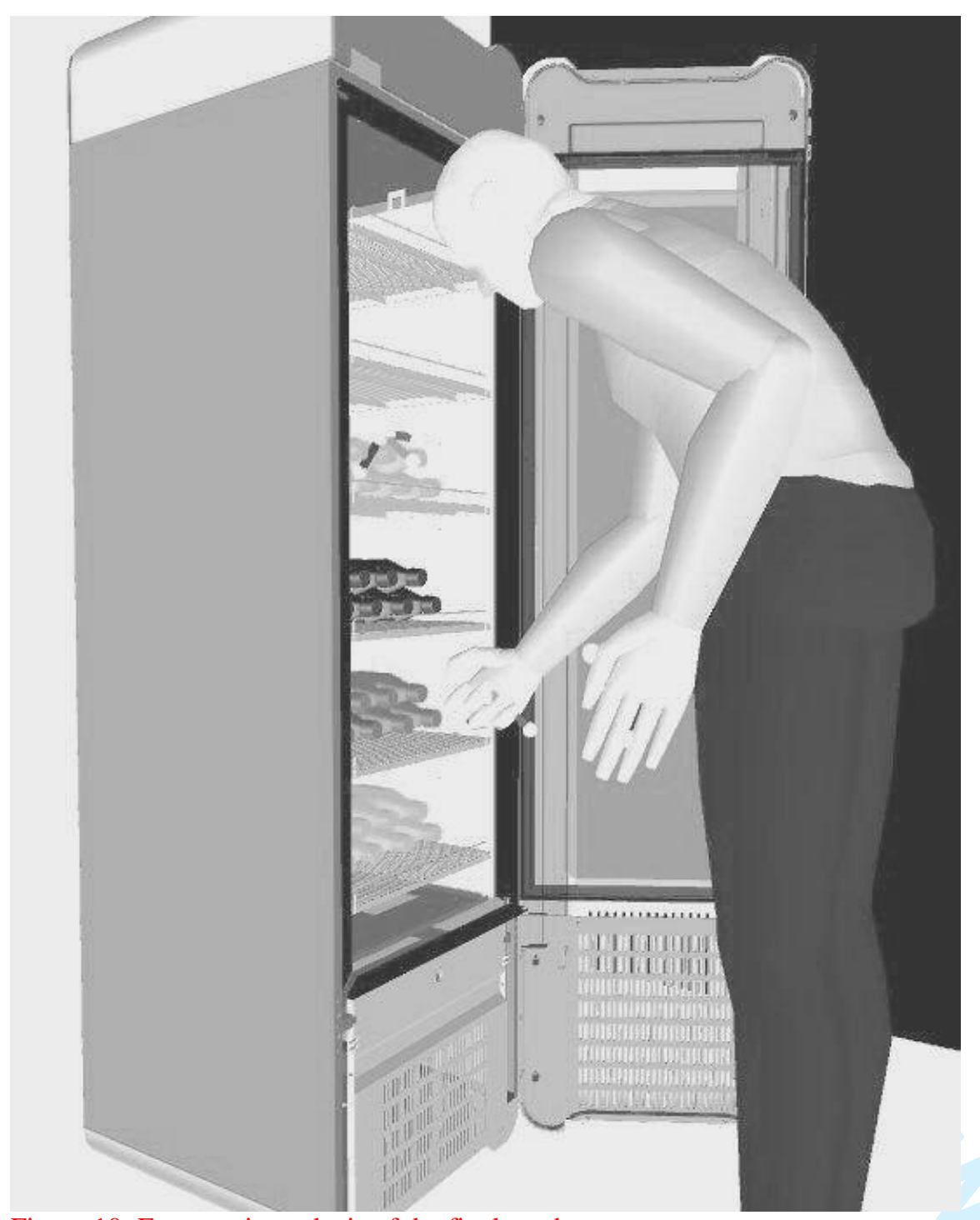

Figure 10: Ergonomic analysis of the final product 
INT. J. COMPUTER INTEGRATED MANUFACTURING

\title{
Development of a web-based collaboration platform for manufacturing product and process design evaluation using virtual reality techniques
}

\author{
M. PAPPAS, V. KARABATSOU, D. MAVRIKIOS and G. CHRYSSOLOURIS*, \\ Laboratory for Manufacturing Systems and Automation (LMS), Department of Mechanical Engineering and \\ Aeronautics, University of Patras, Patras 26500, Greece \\ *Email: gchrys@hol.gr, xrisol@lms.mech.upatras.gr
}

This paper describes the development of a web-based platform for collaborative process and product design evaluation. The Distributed Collaborative Design Evaluation (DiCoDEv) platform provides real-time collaboration of multiple users at different sites on the same project. The innovation concept of this platform lies in the use of Virtual Reality (VR) technology for the development of the working display environment that provides also navigation, immersion and interaction capabilities for all collaborative users in real time. The scope of this work is to provide an efficient robust collaboration tool for the real time validation of a manufacturing product or process, from the early stages of the conceptual design until the latest stages of the production chain. In order to demonstrate the benefits of the virtual collaboration that DiCoDEv platform can provide for manufacturing, a pilot case with a virtual reality environment has been developed based on the requirements of a "real life" manufacturing company.

Keywords: distributed multi-agent systems; collaborative manufacturing; virtual reality; web-based platform; distributed collaborative environments

\section{Introduction}

Today's global business environment in manufacturing industry is characterized by unprecedented competitive pressures and sophisticated customers, who demand innovative and speedy solutions. Understanding and optimizing design processes is a cornerstone of success in these fast-changing environments. A short time to market and maintaining a high quality level of a product have become the main success factors.

Thus, manufacturing companies need to innovate themselves frequently, both by designing new products and by enhancing the quality of the existing ones (Chryssolouris, 2005). Usually, during product design, all the persons involved share a great amount of drawings and assembly models. Often, different components or subassemblies of the product are designed by different groups of designers at geographically different locations. Companies are frequently out-sourcing engineering activities, performed internally, in order to accelerate the design and the product development process (Park et al. 1999). Nowadays, almost 50-80\% of all the components manufactured by original equipment manufacturers are out-sourced to external suppliers (Rezayat 2000). 


\section{Pappas et al.}

However, this policy often creates many comprehension problems due to the lack of an internet based collaborative product design tool, which would effectively disseminate product design knowledge. These problems are typically resolved through meetings or via e-mails and phone discussions. Colleagues are not easily capable of collaborating and exchanging their ideas if they work in different places or even worst, in different countries. A web-based collaborative environment could solve this problem by eliminating unnecessary meetings, repetitive emails and costly product mistakes and delays. The use of such a system aims at identifying, quickly and efficiently, the feasible and the optimal designs through collaboration among product development partners at different locations.

The main goal of the present work is the conceptualization, design and development of a web-based platform for supporting both product data management and real-time collaboration into the same Virtual Environment. The DiCoDEv platform not only does it provide collaboration capabilities among multiple users via the internet, but also immersion and interaction with products and processes under evaluation, through the VRbased working environment. Collaboration features related to users, roles, events, projects and files management together with simulation features, related to process and product design verification using VR, have been developed and incorporated into the integrated web-based platform.

\section{Background work}

Various web-based manufacturing systems have been developed in the past decade for supporting collaborative activities in different life-cycle phases of product development, including marketing, design, process planning, production, distribution, service, etc., and associating these distributed product development life-cycle activities into a globally integrated environment using internet as well as web technologies (Chryssolouris et al. 2004). Many product development software systems, such as CAD, CAM, database management, intelligent knowledge-based, etc., have also been integrated, through web technologies, into these web-based collaboration systems (Yang et al. 2003).

An asynchronous collaborative system has been presented (Craig et al. 2002), called Immersive Discussion Tool (IDT), which emphasizes on the elaboration and transformations of a problem space and underlines the role that unstructured verbal communication and graphic communication can play in design processes. A prototypical system called cPAD has been developed (Shyamsundar et al. 2001, 2002) that enables designers to visualize product assembly models and perform real time geometric modifications, based on polygonized representations of assembly models. The Detailed Virtual Design System (DVDS) for shape modelling in a multi-modal, multi-sensory Virtual Environment (VE) has been presented (Arangarasan et al. 2000), enabling collaborative design and design among multiple designers both in the same site and in remote site virtual environments. An Internet-based virtual reality collaborative environment called Virtual-based Collaborative Environment (VRCE) developed with the use of Vnet, Java and VRML (Kan et al. 2001), demonstrates the feasibility of collaborative design for small to medium size companies that focus on a narrow range of low cost products. A web-enabled PDM system which facilitates various collaborative design activities (Xu et al. 2003) has been developed providing also 3D visualization capabilities. Another tool for dynamic data sharing in collaborative design has been developed (Noel et al. 2003), ensuring that experts may use it as a common space to define and share design entities. A web-based collaborative product design platform for dispersed network manufacturing has been proposed (Zhan et al. 2003). This platform enables authorized users in geographically different locations to have access to the company's product data, such as product drawing files stored at designated servers and to carry out product design work simultaneously and collaboratively on any operating systems.

Further to the research approaches to the field of a web-based collaborative product design, a few commercial tools are available to support such functionalities. OneSpace.net (http://www.cocreate.com/) is a lightweight web collaboration tool that supports online team collaboration for project development. It combines 
Development of a web-based collaboration platform

architecture for web services with familiar concepts, such as organized projects, secure messaging, presence awareness and real time online meetings. IBM's Product Lifecycle Management Express Portfolio is designed specifically for medium-sized companies that design or manufacture products. This system mainly focuses on business processes but also allows design engineers to share 3D data, created with diverse authoring tools and thus, product development can be managed. It includes CATIA Version 5 collaborative product design software and SMARTEAM for product data and release management (http://www.ibm.com/). Matrix10 is designed to support deployments of all sizes. It includes PLM business process applications that cover a wide range of processes including product planning, development and sourcing and program management. The tool furthermore, allows diverse design disciplines to be synchronized around design activities and changes, by reducing the critical errors and cost associated with poor collaboration (http://www.matrixone.com/). eDrawings Professional (http://www.solidworks.com/) is an email-enabled communication tool that eases the review of 2D and 3D product design data across extended product development teams.

Despite the investment made in the last years, both in research and in industrial fields, the global market still lacks in collaboration tools, capable of providing virtual reality techniques as well for product and process design evaluation. Most collaborative tools are more related to a Product Lifecycle Management and less to a purely web-based collaborative platform. Thus, the development of a lightweight web platform that supports the collaborative management, validation and dissemination of product designs/projects as well as the immersive interaction of multiple users with the virtual prototypes, comprise the goals of this research work.

\section{Platform implementation}

The DiCoDEv platform was designed based on an open architecture and Browser/Server technology. The development of the DiCoDEv platform was driven by standard technologies applied to the J2EE language. Such technologies include Java Server Pages (JSP) for visualizing data by creation of HTML pages and Servlets for data manipulation and user interaction. For the Web Server and Servlets container 'Apache Jakarta Tomcat 4.0.4' was used. The development was assisted by 'Borland JBuilder X' as the Integrated Development Environment (IDE) and InterDev together with Oracle 9i development and administration tools for the database design and creation. The development as well as the installation took place on Windows XP Professional Edition operating systems but the same tools, technologies and development processes could be applied to other operating systems, such as Unix.

\subsection{Architecture}

The web platform architecture is following the 3-tier example and includes three layers (Figure 1):

- The Data Layer

- The Business Layer, and

- The Presentation Layer

[Insert figure 1 about here]

These layers communicate through Internet or Intranet, depending on the type of communication.

- Data layer (1st tier): includes the application's database and the connections with all the other external systems as for example an external database for the recovery and storing of data. Some characteristics, such as data locking, consistency and replication ensure the integrity of data. Oracle 9i was used for the platform's database implementation.

- Business layer (2nd tier): consists of the business logic. The architecture of this level can be divided and analyzed furthermore into: The connection mechanism between the mainframe PC and the 


\section{Pappas et al.}

application (JavaServer), the Java Bean Architecture, which contains the work-division planning algorithm and the database interactions, and finally an independent XML unit, which is going to manage the connection between the platform database and the external applications.

- $\quad$ Presentation layer (3rd tier): concerns the clients and consists of the Netscape and Internet Explorer web browsers for this application.

\subsection{User workflow}

The connection among users complies with the Browser User Interface (BUI) models, in a user-friendly Windows environment, which allows the exploitation of all net-place capabilities by using any desired web browser. The user workflow is presented in Figure 2.

User Home Page is the first page and presents information about the number of the new messages in the user's inbox and the number of projects that he/she participates in. Through the Manage Profile page users can change their personal profile. Users can also manage (send/view) all their messages for all the projects they participate in, through the message pages (Manage Messages \& Send/View Message). Once a user has been authorized to the platform he/she is able to participate in an on-line communication and cooperation by exchanging thoughts and ideas with other authorized users through the Chat page. A list of the online users also appears in this page. Moreover, users are able to join specific project-related chat channels.

\section{[Insert figure 2 about here]}

All projects that a user participates in are presented in a list form, in the Manage Workspace page. Information, such as the project's description, the owner and starting date, also appear in this list. If a user is the project owner then he/she has the right to modify the project-related information (name, description, etc.) through the Manage Project page, otherwise he/she can only view this data.

[Insert figure 3 about here]

Through the Manage Users page, the project owners can add/remove active users to their own project, from the list of the authorized users and select their roles for the specific project. Roles are project-related and are specified by the project owners. Through the Manage Project Versions page, the users can manage (view, delete or create) project versions with respect to their authorities in the specific project. The Manage Project Pool page enables users to upload and download files of any type that could be used by all authorized users during the collaborative design process.

In most of the pages, search function and filters are available in order to make the search for specific information easier.

\subsection{Virtual environment}

In order for the DiCoDEv platform to provide virtual collaboration, a commercial VR software tool (DIVISION MockUp2000i2 or dv/MockUp of PTC - http:/www.ptc.com/), is used as a basis for the visualisation and development of the virtual project environments. Ergonomics evaluation of product's design can be also performed in the virtual environment by using an appropriate digital human tool. This system has been integrated into the web platform so as to be directly accessed by users through the platform's GUI. The virtual project environment is used for the visualisation and simulation of products and processes during a collaborative design evaluation scenario. The users are able to create, open, view, modify and save the virtual project environment they work on. All collaborative distributed users can work on the same environment in 
Development of a web-based collaboration platform

real-time either in desktop (Figure 4) or immersive mode, using VR peripheral devices (i.e. Head Mounted Displays, Motion Tracking Systems, Navigation Devises, Data Gloves). A pilot case demonstrating the virtual collaboration capabilities of the DiCoDEv platform is presented in section 5.

[Insert figure 4 about here]

\subsection{Communication}

The communication between the front-end and the platform's database is achieved by Oracles' drivers. The web interface provides access to the portal and runs on a Windows 2000 or XP Operating System. A 128kbps ISDN (or DSL) line is capable of confronting with the data load during a collaborative session. Through this communication, the authorized users can upload/download the required virtual project environment and information. By the time the project-related files are uploaded, a new version of the selected project is automatically created into the database.

The communication between the front-end and the back-end external application (dv/MockUp) enables authorized users to open and modify a virtual project environment and it is realized through the XML protocol (Figure 5).

Communication between the DiCoDEv platform and other external applications, such as databases is also feasible.

[Insert figure 5 about here]

\section{Platform functionality}

The key features of the DiCoDEv platform have been implemented so as to cover both the development standards of the web-based applications and the requirements of a typical industrial virtual collaborative scenario.

\subsection{Collaborative functions}

The developed collaborative functions enable the management of users and data as well as real-time collaboration. The supported collaboration functions are:

- Security: The Platform Administrator has the overall security management of the system and provides the users with passwords. Every user has to give his login and password in order to have access to the platform's data. Moreover, in order to eliminate spamming phenomena, filters and disk-storage limitations are provided.

- Users/roles management: This function enables the management of the security and the rights on every file within a project depending on the predefined role of each user. Based on the user's role, the system provides him/her with specific access rights to the various platform's features, information and capabilities.

- Messages/chat: E-mails and chat (Figure 6) are supported to enable authorized users to communicate with each other. This function allows participants to exchange easily and quickly ideas about a new product and improves decision making in product or process design verification, allowing issues that could hinder a project's progress to be quickly removed by team members. 


\section{Pappas et al.}

[Insert figure 6 about here]

- File sharing: This function enables authorized users to easily send and receive large files via internet without the hassle of FTP or the limitations of the e-mails' providers.

- File storage/versioning: File storage and versioning is provided through the platform's database. Several types of files (drawings, documents, 3D models, textures, etc.) could be stored and retrieved by the users. An automatic and easy-to-use mechanism for file versioning has been developed in order to help involved users to review the history of modifications of every project-related file.

- File browser/info: A user friendly web-based interface allows authorized users to create, delete, edit, copy, rename, move, download and upload files and directories. It has been designed for rapid adoption throughout an organization, requiring little or no training to get familiar with it in order to enable the quick search of any required information stored into the database.

\subsection{Virtual reality functions}

These functions have been implemented into the dv/MockUp to allow the visualisation and functional simulation of products and processes as well as the users' immersion and interaction within the virtual environment. The basic Virtual Reality functions are:

- Behavioural simulation: Behavioural simulation controls the functional characteristics of the virtual systems involved in the process performance. Based on the event/action engine of dv/MockUp, developers can model complex behaviours in the virtual environment (assembly joint constraints, part movement restrictions etc.), in order for the virtual objects to 'behave' in a real-life like manner.

- Assembly: This function allows the accurate assembly execution within the virtual environment. During an assembly process, the part to be assembled is released from the user's hand, so as to be assembled in its final position, as soon as a good positional and rotational orientation has been achieved (magnet concept). This orientation is very close to the exact final mounting position. The field of the 'magnet' can be adjusted to account for various levels of fitting precision (Figure 7).

[Insert figure 7 about here]

- Collision detection: Dynamic clash detection is provided within the simulation environment among static parts and either moving parts or the user's hands. In this way, visual and acoustic alerts enable the user to verify the feasibility of a process, in terms of reachability of picking and mounting locations and handlability of parts.

\section{Pilot application}

In order to demonstrate the benefits of the virtual collaboration that DiCoDEv platform can provide for manufacturing, a virtual reality environment has been developed based on the requirements of a commercial refrigerators' company. The environment represents a typical milk-shop with refrigerators (Figure 8) and collaboration has been performed between different users in order to review these refrigerators in terms of design (i.e. capacity, ergonomics, door handle selection, etc.) and of appearance (i.e. colors, textures, logos, materials, etc.) before proceeding in the production phase.

[Insert figure 8 about here] 
Development of a web-based collaboration platform

Several collaborative sessions have been performed showing the capability of real-time collaboration among different users. They can use all the virtual reality functions of the environment (Figure 9) as well as the ergonomics evaluation, using digital humans in the virtual environment (Figure 10). Immersion capability is also available for realistic human interaction.

[Insert figure 9 about here]

[Insert figure 10 about here]

During a multi-user collaborative session, each participant has its own copy of the graphical user interface (GUI), which provides a rendered 3D view of the virtual product. All users can interact with the virtual product at any time, with no restriction on the number of simultaneous interactions. The changes made by a user are immediately visible to the others. Real-time chat capabilities enable the continuous communication among the online users. Moreover, a user can be represented by an animated manikin figure called avatar. Any number of users can join a collaborative session using TCP/IP over local or WAN networks. In order to use the DiCoDEv platform there is no enforcement on the use of specific Operational System or VR peripherals.

The integration of the DiCoDEv platform with Virtual Reality provides an advanced environment in the network as a common virtual design space in which people can simultaneously work during the product life cycle. The developed pilot environment enables:

- The cooperation among distributed designers and manufactures during the refrigerator design stage

- The real-time multi-user interaction into the same virtual prototype/design

- The effective and efficient use, sharing, and simulation of design and manufacturing data through the web (e.g. ideas, drawings, 3D-models, analysis results, ...)

- The ergonomics evaluation of the products using digital humans (manikins) that represent different user populations

- Activities in a many-to-many session within a common virtual space (e.g. conceptual design, virtual prototyping, assembly execution, ergonomic analysis, ...)

- The exchange of ideas and of comments based on the 3D representation of the product

- The advanced product demonstration through the web (a virtual web showroom)

\section{Conclusions}

In this paper, a web-based virtual collaborative platform called DiCoDEv - Distributed Collaborative Design Evaluation platform that can be used during manufacturing product and process design evaluation, is presented. Providing a multi-user real-time collaboration as well as a VR-based product and process verification, this platform is an integrated tool for designers, engineers and managers.

The DiCoDEv platform allows multiple users to work in collaborative and distributed way, decreasing considerably the time required for the designing phase to be completed. This work focuses on improving team productivity, providing the infrastructure necessary to make the engineering teams efficient, even if they are dispersed over different sites, without changing the existing design environment. The platform's integration into the VR environment enables the immersion and interaction of users with the virtual prototypes that lead to the efficient evaluation of product and process designs where the human intervention is crucial. The benefits of using the virtual capabilities of the DiCoDEv platform include:

- Multi-user visualization, immersion and interaction

- Real-time collaboration on the same virtual design 


\section{Pappas et al.}

- Simultaneous review and maintain alternative virtual designs

- Ergonomics evaluation using digital human simulation

\section{Acknowledgement}

This work was partially supported by the Greek national research project e-MERIT/EB-26, funded by the General Secretariat of Research and Technology (GSRT).

\section{References}

Arangarasan, R. and Gadh, R., Geometric modelling and collaborative design in a multi-modal multi-sensory virtual environment, in proceeding of the ASME 2000 Design Engineering Technical Conferences and Computers and Information in Engineering Conference, 2000, pp. 10-13.

Chryssolouris, G., Manufacturing Systems: Theory and Practice, $2^{\text {nd }}$ edition. 2005 (Springer-Verlag: New York).

Chryssolouris, G., Makris, S., Xanthakis, V. and Mourtzis, D., Towards the internet based supply chain management for the shiprepair industry. International Journal of Computer Integrated Manufacturing, 2004, 17(1), 45-57.

Chryssolouris, G., Makris, S., Papakostas, N. and Xanthakis, V., A cooperative software environment for planning and controlling ship-repair contracts, in proceedings of the 4th International Conference on e-Engineering \& Digital Enterprise Technology, 2004, pp. 321-330.

Craig, D. L. and Craig, Z., Support for collaborative design reasoning in shared virtual spaces. Automation in Construction, 2002, 11(2), 249-259.

Kan, H. Y., Duffy, V. G. and Su, C. J., An internet virtual reality collaborative environment for effective product design. Computers in Industry, 2001, 45, 197-213.

Noel, F. and Brissaud, D., Dynamic data sharing in a collaborative design environment. International Journal of Computer Integrated Manufacturing, 2003, 16(7-8), 546-556.

Park, H. and Cutkosky, M. R., Framework for modeling dependencies in collaborative engineering processes. Research in Engineering Design - Theory, Applications, and Concurrent Engineering, 1999, 11, 84 102.

Rezayat, M., The enterprise - web portal for life cycle support. Computer Aided Design, 2000, 32(2), 85-96.

Shyamsundar, N. and Gadh, R., Internet-based collaborative product design with assembly features and virtual designspaces. Computer Aided Design, 2001, 33, 637-651.

Shyamsundar, N. and Gadh, R., Collaborative virtual prototyping of product assemblies over the Internet. Computer Aided Design, 2002, 34, 755-768.

$\mathrm{Xu}, \mathrm{X} . \mathrm{W}$., and Liu, T., A web-enabled PDM system in a collaborative design environment. Robotics and Computer-Integrated Manufacturing, 2003, 19(4), 315-328.

Yang, H. and Xue, D., Recent research on developing Web-based manufacturing systems: a review. International Journal of Product Research, 2003, 41(15), 3601-3629.

Zhan, H. F., Lee, W. B., Cheung, C. F., Kwok, S. K. and Gu, X.J., A web-based collaborative product design platform for dispersed network manufacturing. Journal of Materials Processing Technology, 2003, 138, 600-604. 


\section{Development of a web-based collaboration platform}

Figure 1: 3-tier system architecture

Figure 2: DiCoDEv platform user workflow

Figure 3: Manage Project page

Figure 4: Collaborative design through the DiCoDEv platform

Figure 5: Interface between web-platform's GUI and dv/MockUp

Figure 6: Chat page of DiCoDEv web platform

Figure 7: Visualization of the assembly function (magnet concept)

Figure 8: Virtual environment of the pilot application

Figure 9: Real-time collaboration capability

Figure 10: Ergonomic analysis of the final product 
M. Pappas et al.

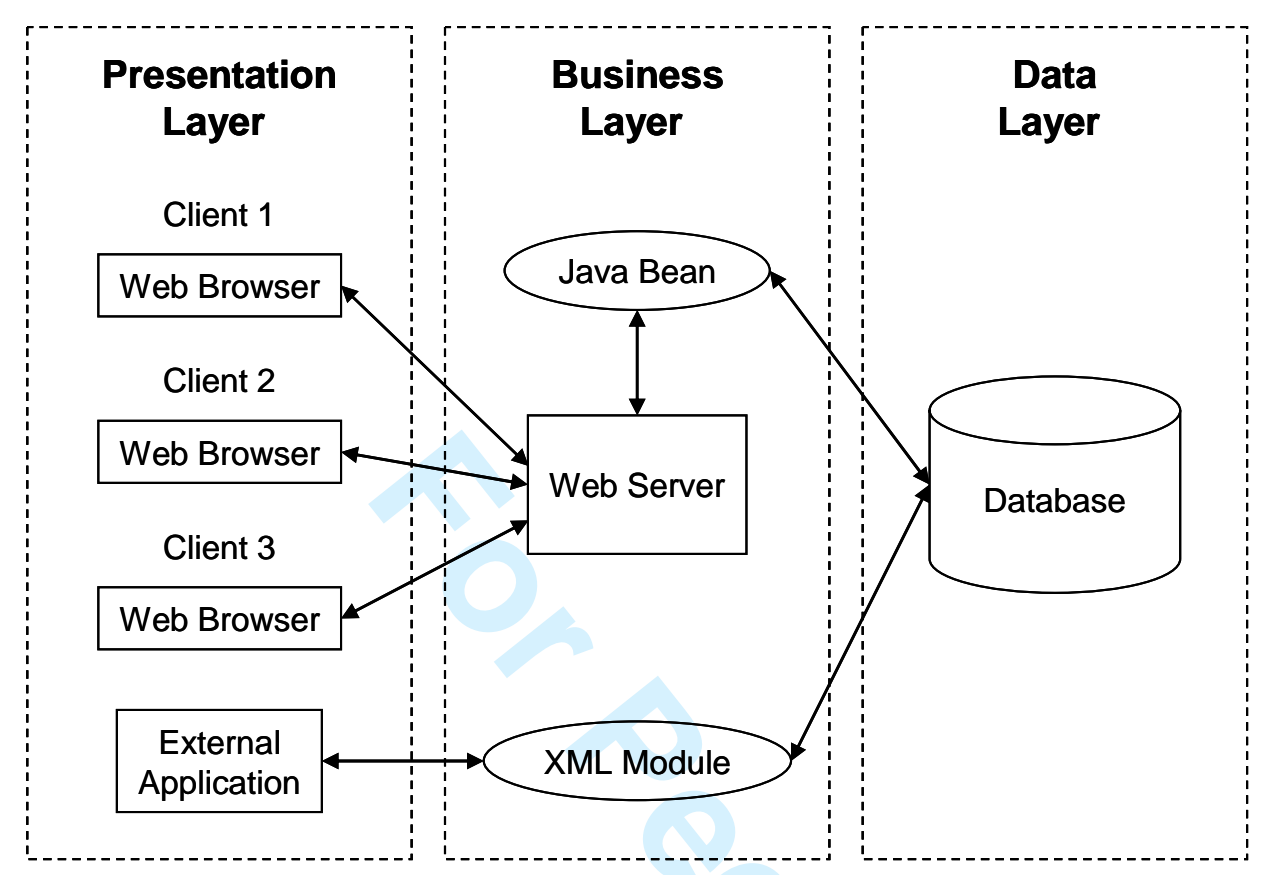


Development of a web-based collaboration platform

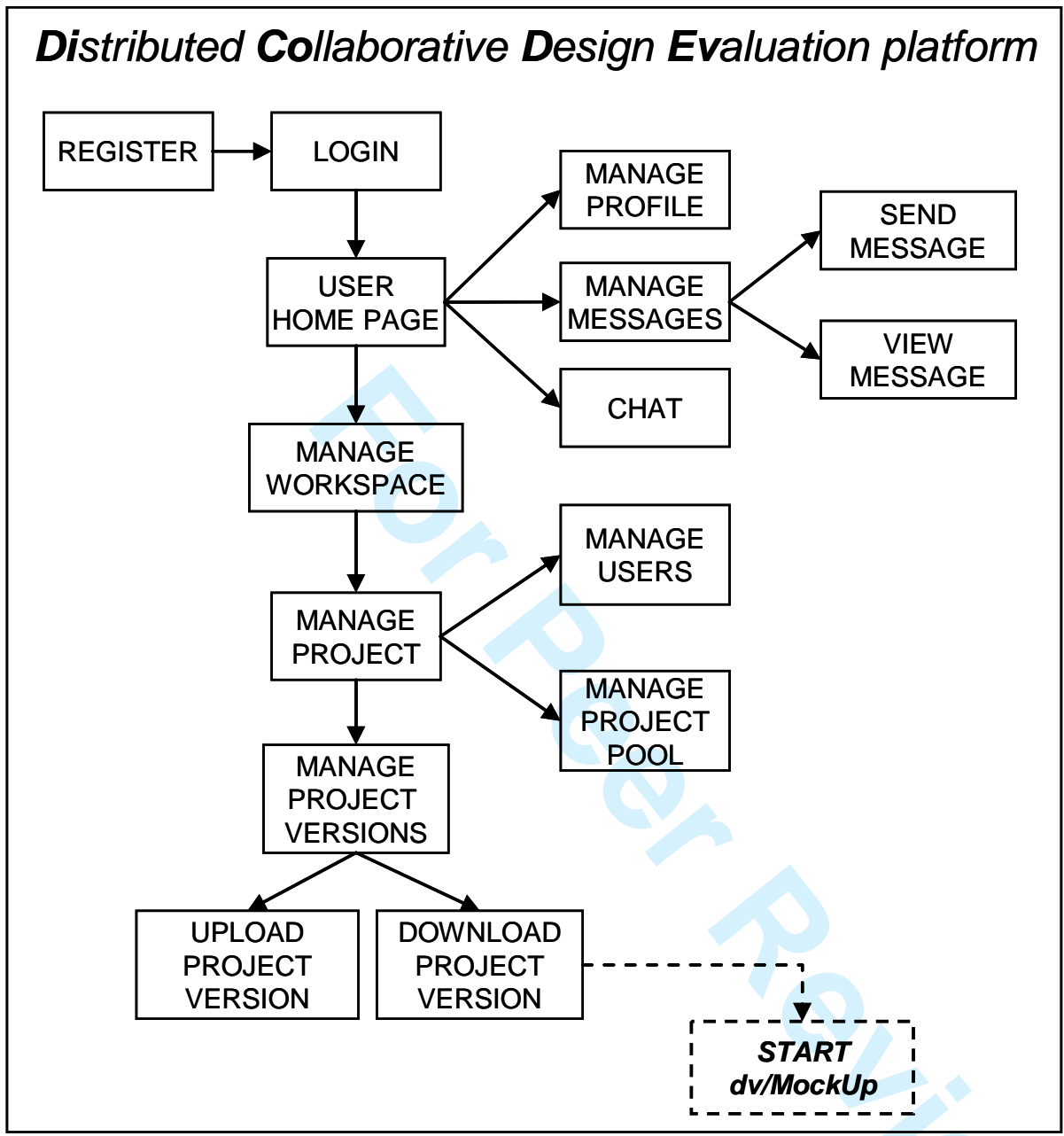


M. Pappas et al.

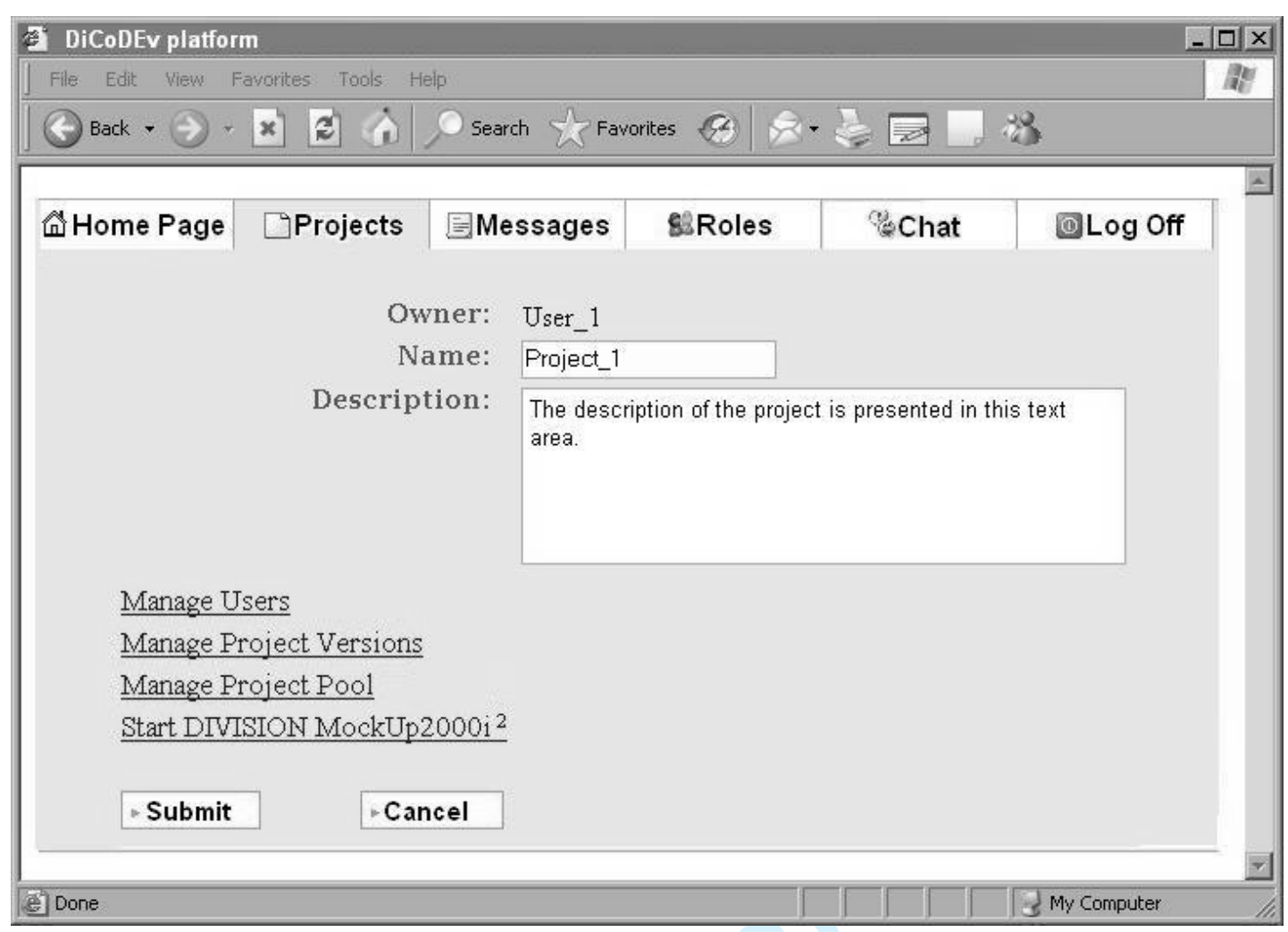

URL: http://mc.manuscriptcentral.com/tandf/tcim Email:ijcim@bath.ac.uk 
Development of a web-based collaboration platform

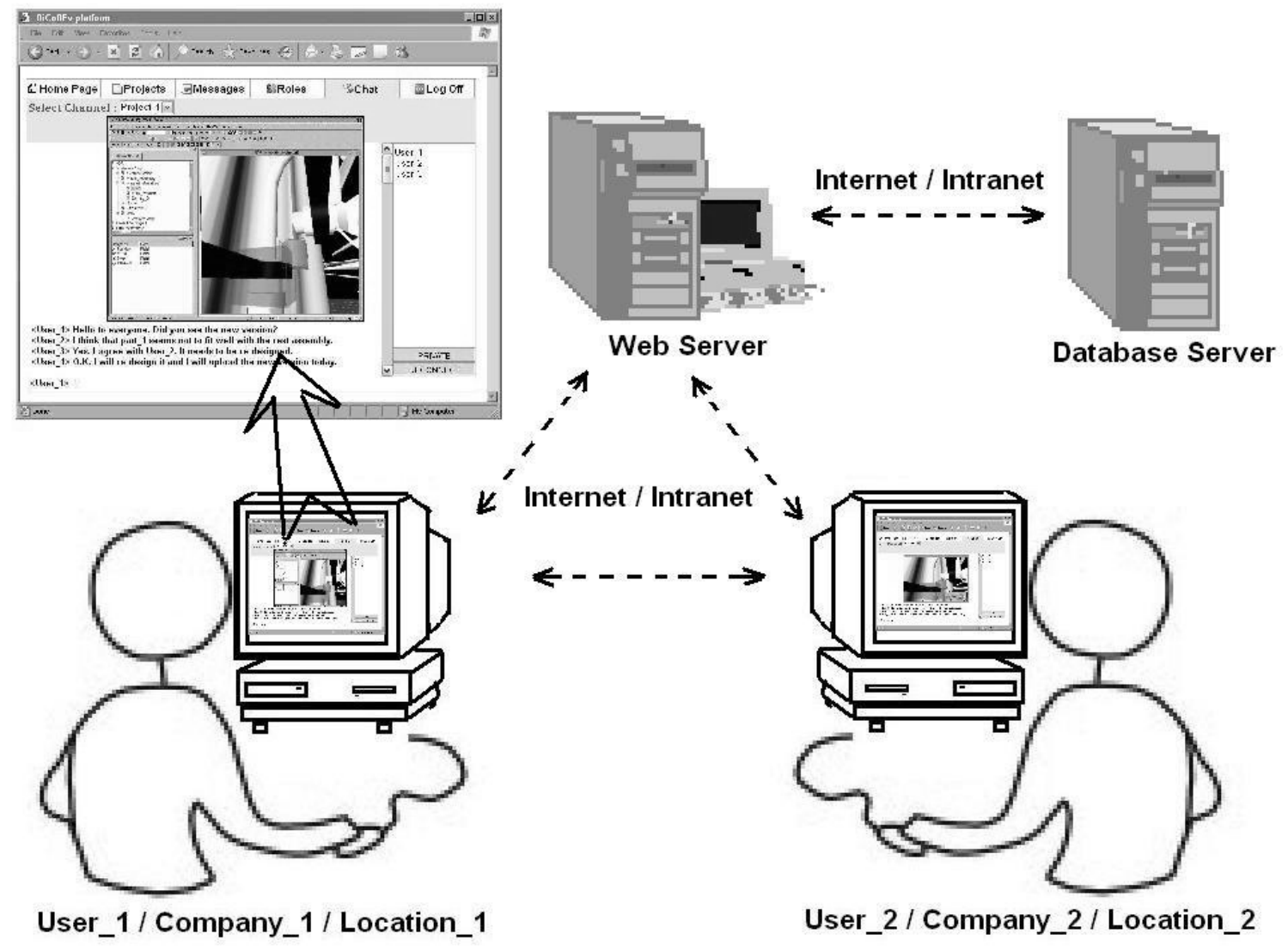


M. Pappas et al.

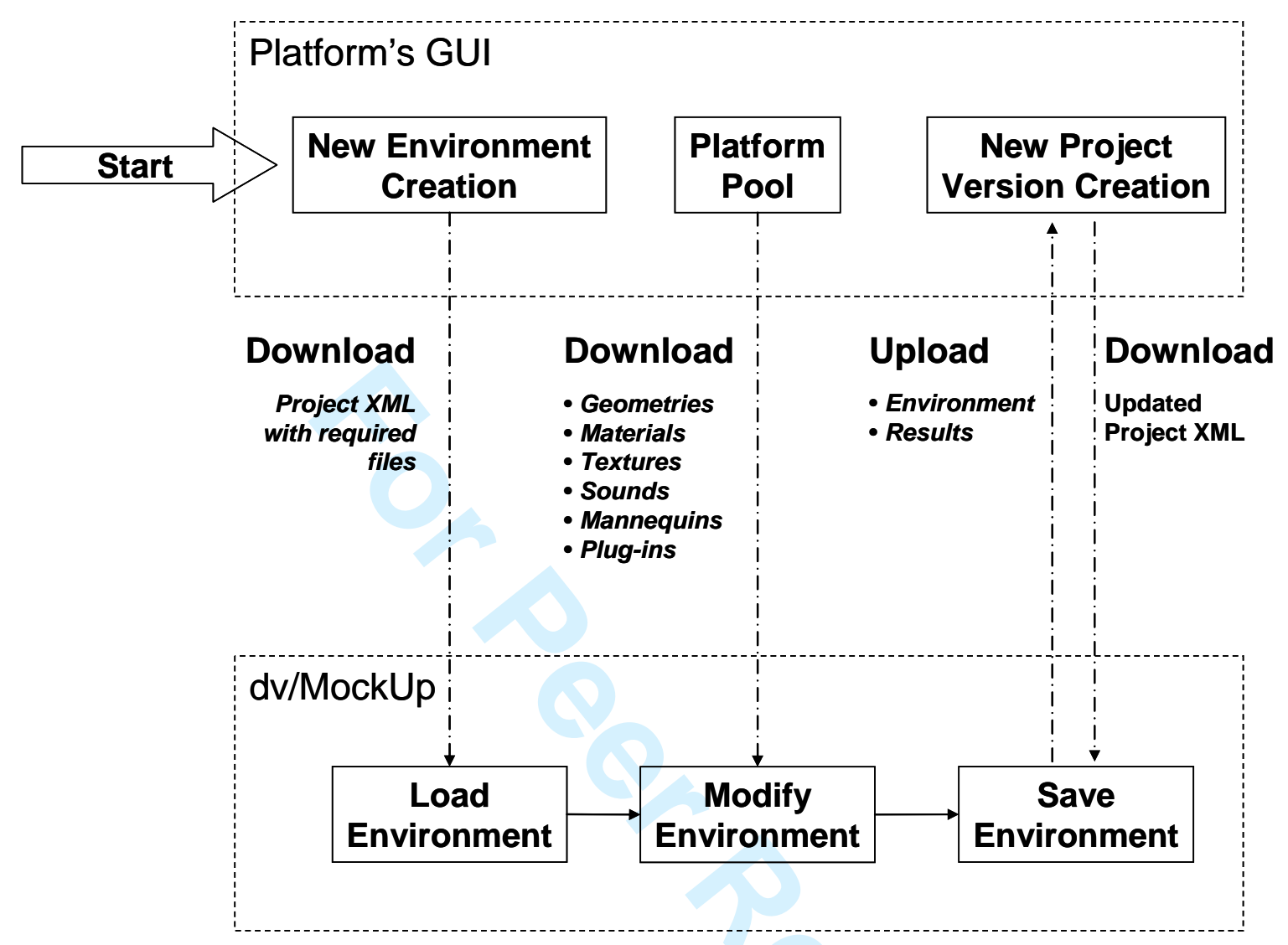


Development of a web-based collaboration platform

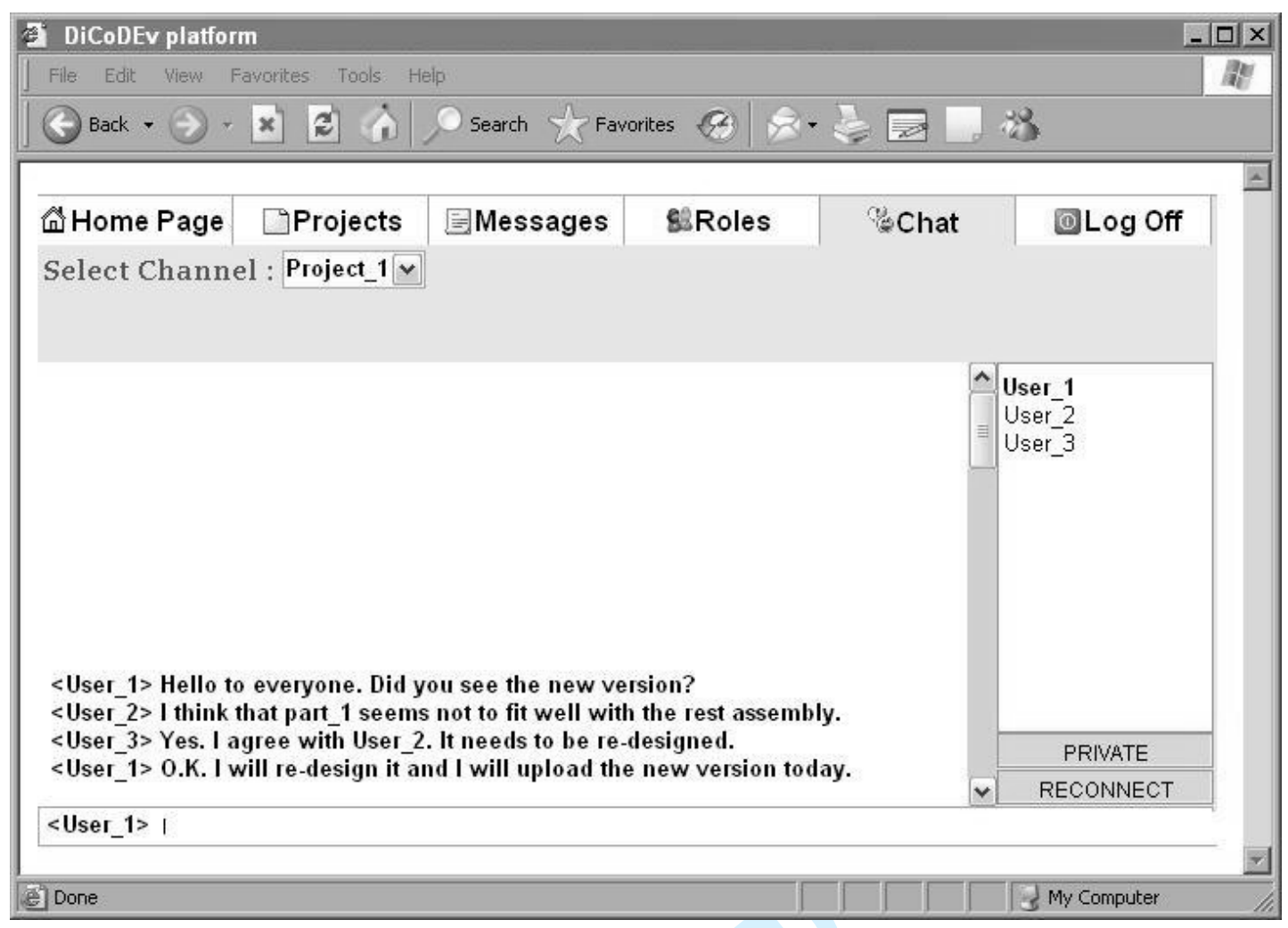


M. Pappas et al.

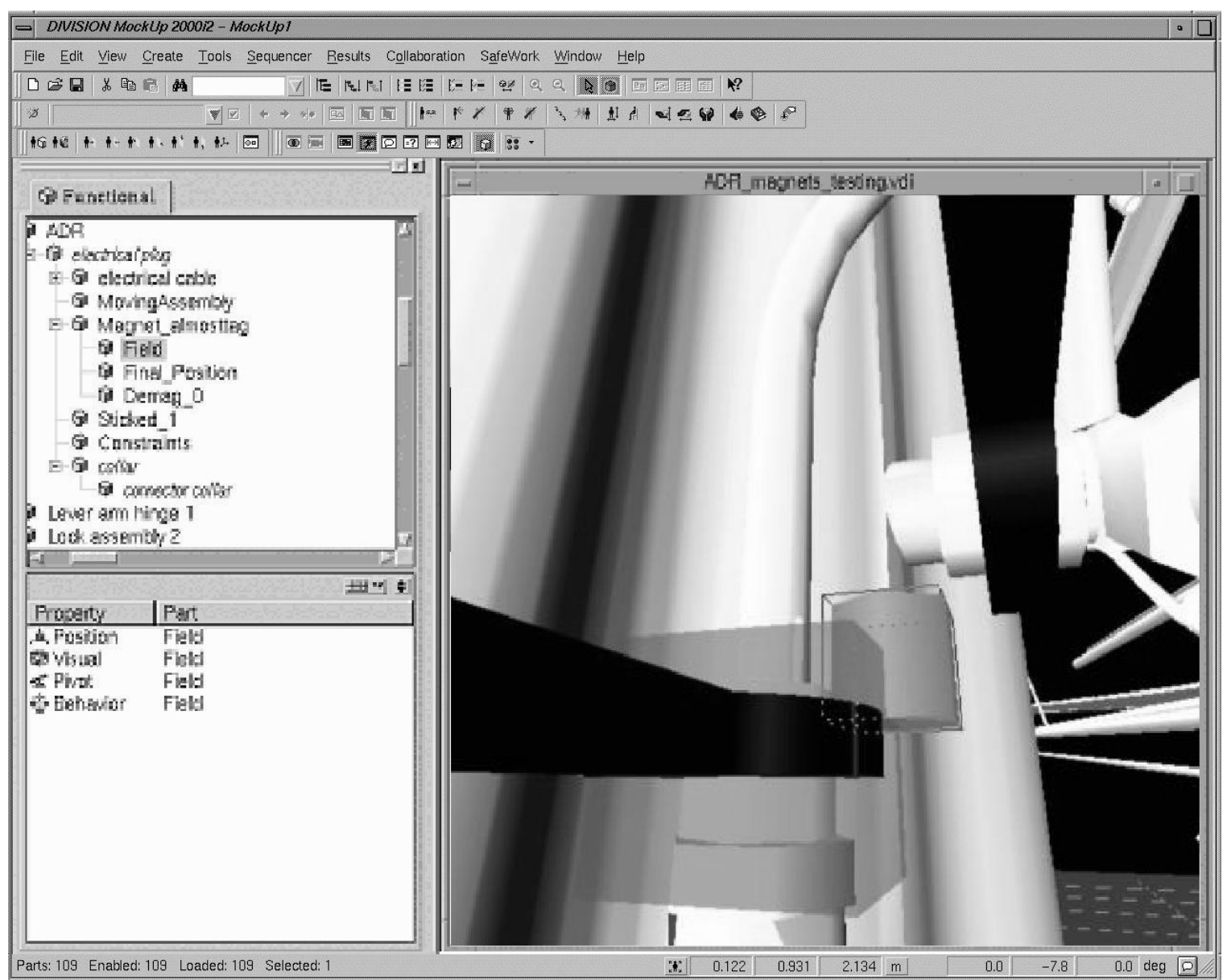


Development of a web-based collaboration platform

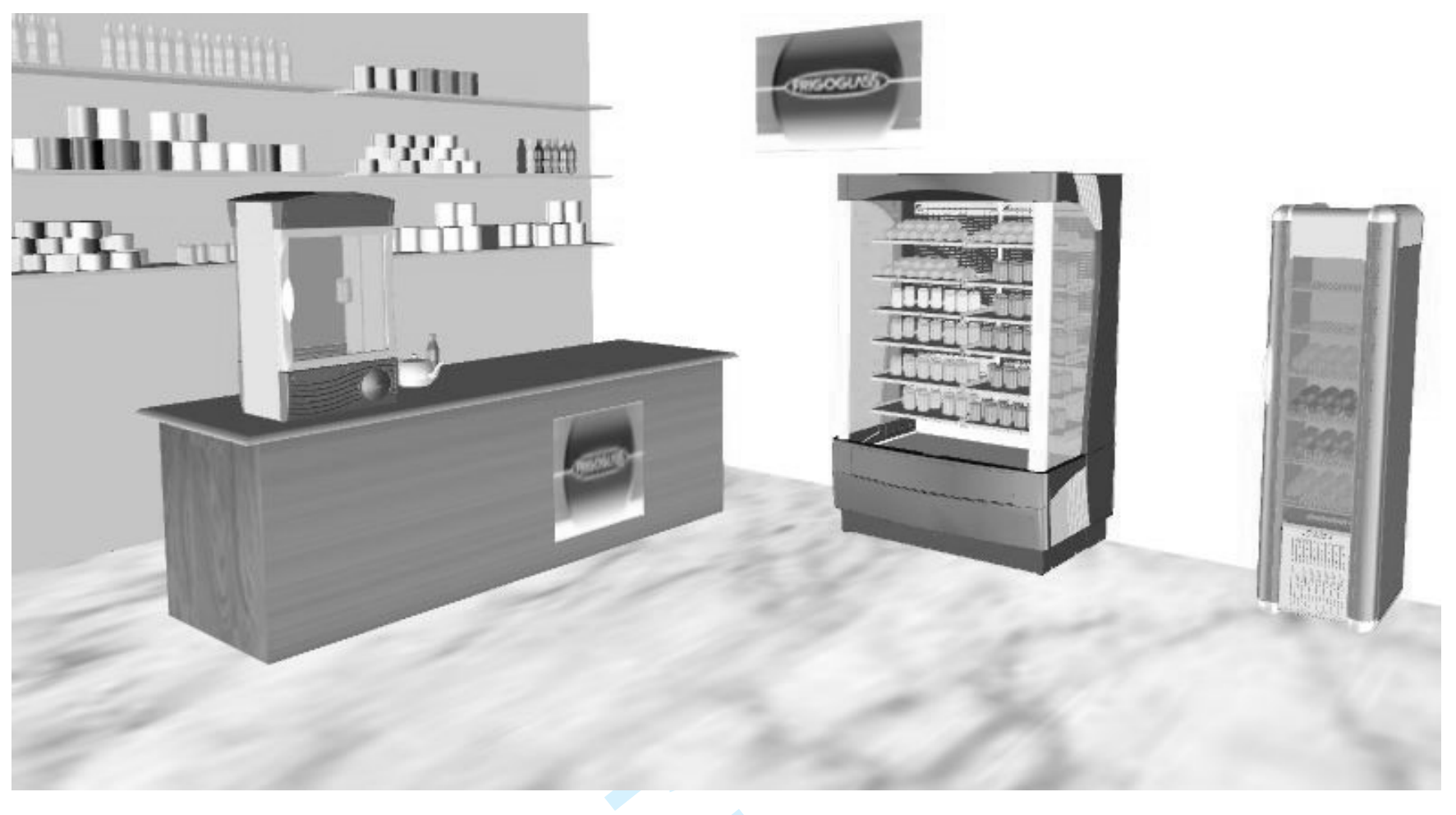




\section{Pappas et al.}

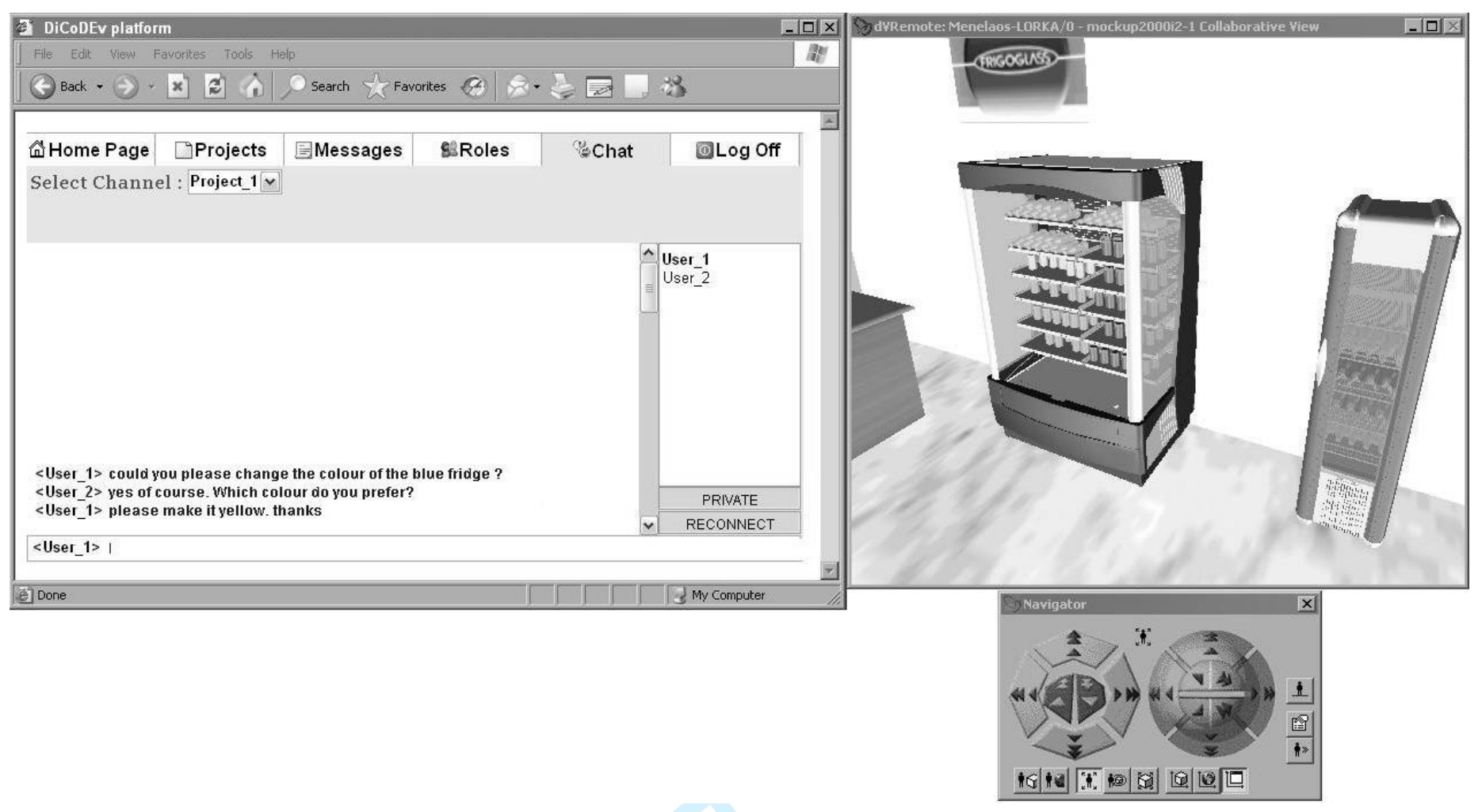


Development of a web-based collaboration platform

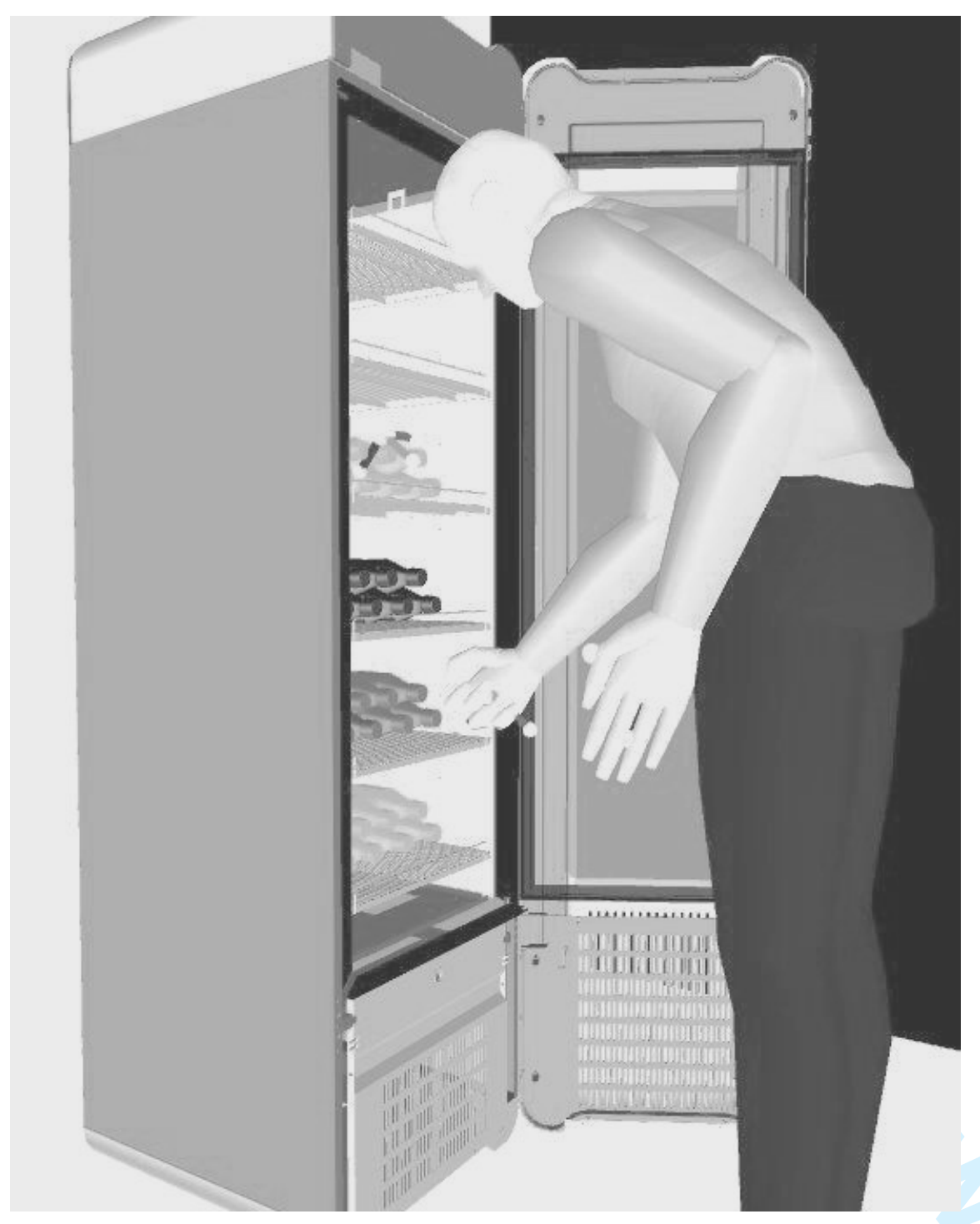

